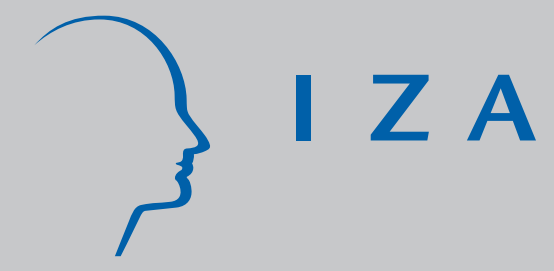

IZA DP No. 531

Unemployment in the European Union:

A Dynamic Reappraisal

Marika Karanassou

Hector Sala

Dennis J. Snower

J uly 2002 


\title{
Unemployment in the European Union: A Dynamic Reappraisal
}

\author{
Marika Karanassou \\ Queen Mary, University of London and IZA Bonn \\ Hector Sala \\ Universitat Autónoma de Barcelona \\ Dennis J. Snower \\ Birkbeck College, University of London, \\ CEPR and IZA Bonn
}

\author{
Discussion Paper No. 531 \\ July 2002
}

\author{
IZA \\ P.O. Box 7240 \\ D-53072 Bonn \\ Germany \\ Tel.: +49-228-3894-0 \\ Fax: +49-228-3894-210 \\ Email: iza@iza.org
}

This Discussion Paper is issued within the framework of IZA's research area The Welfare State and Labor Markets. Any opinions expressed here are those of the author(s) and not those of the institute. Research disseminated by IZA may include views on policy, but the institute itself takes no institutional policy positions.

The Institute for the Study of Labor (IZA) in Bonn is a local and virtual international research center and a place of communication between science, politics and business. IZA is an independent, nonprofit limited liability company (Gesellschaft mit beschränkter Haftung) supported by the Deutsche Post AG. The center is associated with the University of Bonn and offers a stimulating research environment through its research networks, research support, and visitors and doctoral programs. IZA engages in (i) original and internationally competitive research in all fields of labor economics, (ii) development of policy concepts, and (iii) dissemination of research results and concepts to the interested public. The current research program deals with (1) mobility and flexibility of labor, (2) internationalization of labor markets, (3) the welfare state and labor markets, (4) labor markets in transition countries, (5) the future of labor, (6) evaluation of labor market policies and projects and (7) general labor economics.

IZA Discussion Papers often represent preliminary work and are circulated to encourage discussion. Citation of such a paper should account for its provisional character. A revised version may be available on the IZA website (www.iza.org) or directly from the author. 
IZA Discussion Paper No. 531

July 2002

\section{ABSTRACT \\ Unemployment in the European Union: A Dynamic Reappraisal ${ }^{*}$}

This paper examines the movements in EU unemployment from two perspectives: (a) the NRU/NAIRU perspective, in which unemployment movements are attributed largely to changes in the long-run equilibrium unemployment rate and (b) the chain-reaction perspective, in which unemployment movements are viewed as the outcome of the interplay between labor market shocks and prolonged lagged adjustment processes. We present an empirical analysis that distinguishes between unemployment movements arising from longrun equilibrium changes and those arising from lagged intertemporal adjustments. This analysis has far-reaching policy implications. Our analysis shows that the rise in EU unemployment over the 1970s and first part of the 1980s was due largely to permanent shocks (especially the rise in working-age population and the decline in capital formation), whereas the unemployment increase in the first part of the 1990s was due largely to temporary shocks (especially the fall in competitiveness and the rise in real interest rates).

JEL Classification: J32, J60, J64, E30, E37

Keywords: unemployment, natural rate, NAIRU, labor market shocks, employment, labor force participation, wage determination, intertemporal adjustments, homogeneous dynamic panels, panel unit root tests

Dennis Snower

Department of Economics

Birkbeck College

University of London

7 Gresse Street

London W1P 1PA

Tel.: +44 (207) 6316408

Email: dsnower@economics.bbk.ac.uk

\footnotetext{
* We gratefully acknowledge the financial support from the following sources: for all authors, IZA, Bonn, for the project on "Reappraising Europe's Unemployment Problem"; for Marika Karanassou, the ESRC Grant No.R000239139; and for Hector Sala, the Fundacion Banco Herrero.
} 


\section{Introduction}

There are two fundamentally different economic views of unemployment: (i) In the frictionless equilibrium view, labor markets adjust quickly to external shocks (such as shocks to productivity, oil prices, or interest rates) and thus these markets spend most of the time at or near their long-term equilibrium positions. Thus the long-term equilibrium unemployment rate - at which there is no tendency for the participants to change their behavior, given the exogenous variables they face in each period of time - is a good approximation of the actual unemployment rate. (ii) In the prolonged adjustment view, labor markets adjust only slowly to external shocks, on account of adjustment costs. Consequently, the actual unemployment rate can be away - possibly far away - from its long-term equilibrium for substantial time spans.

Naturally, these two views are not mutually exclusive. On the contrary, most economists view them as polar extremes, and believe that labor market activity in practice lies in the interior of a spectrum between these extremes. Where, however, on this spectrum we find ourselves turns out to be a matter of considerable importance, not only for our conceptual understanding of unemployment movements, but also for predictive and policy purposes.

The theories of the "natural rate of unemployment" (NRU) or "non-accelerating inflation rate of unemployment" (NAIRU) generally lie closer to the frictionless equilibrium view than the prolonged adjustment view. These theories usually imply that European unemployment has tended to increase, from one recession to the next over the past three decades, because the long-run equilibrium unemployment has increased. These long-run changes have been ascribed to a variety of factors, such as generosity and duration of unemployment benefits, tax increases, interest rate increases, changes in the terms of trade, unionization, demographic factors, and so on. The NRU and NAIRU theories do allow some adjustment dynamics, but these transition effects are generally assumed to work themselves out in the course of a short period - say, one or two years - and thus they cannot be responsible for the long-climb in European unemployment from one business cycle to the next.

The "chain reaction theory of unemployment", on the other hand, is an expression of the prolonged adjustment view. This theory views the movements of European unemployment as the outcome of the interplay between a series of labor market shocks and prolonged adjustments to these shocks. In this context, each labor market shock has a chain reaction of unemployment effects, extending through time. ${ }^{1}$ The chain reactions arise from interactions among different (often

\footnotetext{
${ }^{1}$ The theory - described, for example, in Karanassou and Snower (1997, 1998) and Henry, Karanassou and Snower (2000) - derives its initial inspiration from the large literature on un-
} 
complementary) lagged adjustment processes, as well as interactions between the dynamic structure of the shocks and the adjustment processes system.

Permanent labor market shocks generally shift the long-run unemployment equilibrium, as well as generate a chain reaction of intertemporal unemployment effects. The speedier is the intertemporal adjustment process, the faster will the labor market approach its long-run equilibrium, and thus the greater the explanatory power of the frictionless equilibrium approach. On the other hand, the longer it takes for the lagged adjustment mechanisms to work themselves out, the longer the labor market will be away from its long-run equilibrium in the aftermath of labor market shocks, and thus the greater the value-added of the prolonged adjustment approach.

This paper examines unemployment in the European Union (EU) from these two perspectives. We present an empirical analysis that distinguishes between unemployment movements arising from long-run equilibrium changes and those movements arising from lagged intertemporal adjustments.

The adjustment dynamics to temporary and permanent labor market shocks are quite different, as we will show. Thus, to conduct a careful empirical analysis of lagged adjustments, we need to divide the exogenous variables of our empirical model into temporary components $(T C s)$ and permanent components $(P C s)$, whose changes are the temporary and permanent shocks.

On this basis, we decompose the European unemployment trajectory into

- "temporary unemployment repercussions" $(\mathcal{T})$ which constitute the unemployment trajectory resulting from the $T C s$, and

- "permanent unemployment repercussions" $(\mathcal{P})$ which comprise the unemployment trajectory generated by the $P C s$.

The temporary and permanent repercussions may, in turn, be divided into (a) the long-run unemployment effects of the TCs and $P C s$, which we denote by $u_{t}^{L R}(T C)$ and $u_{t}^{L R}(P C)$ and (b) the dynamic adjustments toward these long-run effects.

Let us define the frictionless equilibrium unemployment rate (FEU), at time $t$, as that unemployment rate at which there is no tendency for the unemployment rate to change (at time $t$ ), given the values of the exogenous variables (at time $t$ ) in the underlying labor market model. In other words, the FEU is the unemployment rate that would obtain once all the lagged adjustment processes have worked themselves out, period by period, given the exogenous variables. Thus the FEU can be identified as the sum of the long-run unemployment effects of the temporary

employment persistence and hysteresis (e.g. Blanchard and Summers (1986) and Lindbeck and Snower (1987)). 
and permanent components: $F E U_{t}=u_{t}^{L R}(T C)+u_{t}^{L R}(P C)$. The FEU is often identified with the natural rate of unemployment.

The above relationships are summarized in Figure 1.

\section{Figure 1: The Structure of the Shocks and the Frictionless Equilibrium Unemployment Rate}

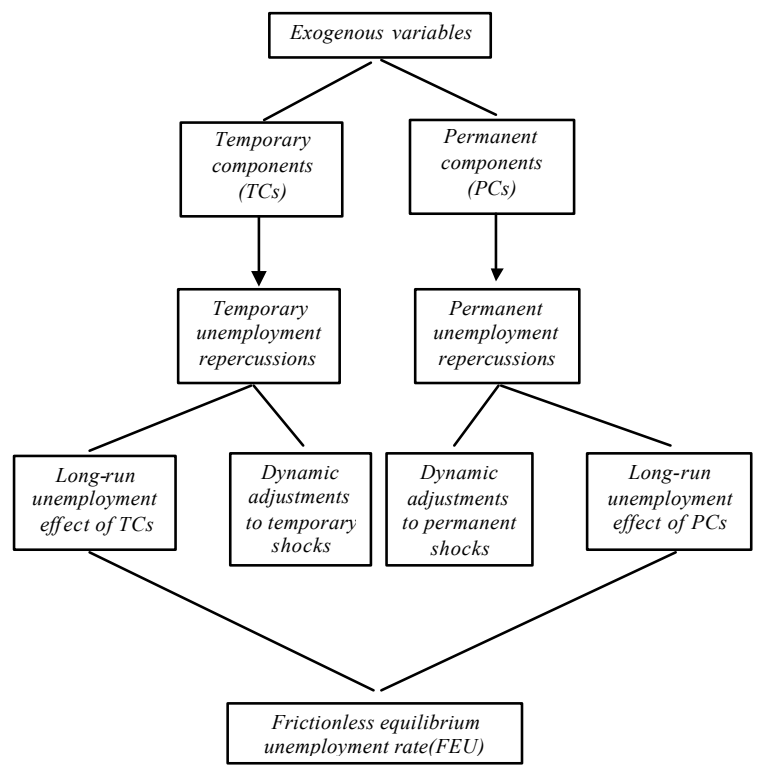

By examining the dynamic implications of temporary and permanent shocks, this paper avoids a pervasive propensity in much of the NRU/NAIRU literature to ignore or avoid lagged adjustment processes through various methods, such as predicting unemployment on the basis of five-year averages of exogenous variables. ${ }^{2}$ We argue that only once the dynamics are taken seriously, can the explanatory power of the FEU and chain reaction theories be compared fairly. If lagged adjustment processes are ignored in modeling unemployment, it is circular reasoning to conclude that these processes have no major role to play in determining unemployment movements.

If the lagged adjustment processes in the labor market work themselves out quickly, then the temporary and permanent repercussions $(\mathcal{T}$ and $\mathcal{P})$ will remain

\footnotetext{
${ }^{2}$ This is a common practice in the labor markets literature. See, for example, Blanchard and Wolfers (2000), Daveri and Tabellini (2000) and Phelps and Zoega (2001). Blanchard and Wolfers (2000, p. 19C) provide a justification for this approach: "There seems to be little point in looking at year-to-year movements in institutions or in shocks unless one wants to learn more about dynamic effects, and this would take us too far. So, as in earlier figures, we divide time into 8 five-year periods, from 1960-64 to 1995+".
} 
close to the long-run unemployment effects of the temporary and permanent components $\left(u_{t}^{L R}(T C)\right.$ and $\left.u_{t}^{L R}(P C)\right)$, respectively, and thus the sum of the temporary and permanent repercussions $(\mathcal{T}+\mathcal{P})$ will follow the FEU $\left(u_{t}^{L R}(T C)+\right.$ $\left.u_{t}^{L R}(P C)\right)$ closely. However, if the lagged adjustment processes are lengthy, then the sum of the temporary and permanent repercussions may not track the FEU closely, since it may take a long time for the full effects of the temporary and permanent shocks to work themselves out.

This is the context in which we investigate the roles of the FEU theory versus the chain reaction theory in explaining EU unemployment movements. Our empirical analysis shows that adverse permanent shocks - particularly a rise in working-age population and a decline in capital formation accompanying the productivity slow-down - played a major role in accounting for the rise in European unemployment over the 1970s and first half of the 1980s; but adverse temporary shocks - particularly falling competitiveness, a rise in the real interest rate, and further temporary shocks associated with capital formation - were important in explaining the unemployment increase in the first half of the 1990s. Furthermore, our analysis shows that lagged labor market adjustment processes played a very important role in modifying the unemployment effects of the temporary and permanent shocks. In particular, these adjustment processes prevented the full effects of the adverse permanent shocks from manifesting themselves right away; in fact, their influence was felt only gradually and progressively over the 1970s and first half of the 1980s. Similarly, the favorable permanent shocks since then also had delayed effects, contributing substantially to the recoveries in the late 1980s and late 1990s. Finally, the adjustment processes played a substantial role in smoothing the influence of the temporary shocks and giving them persistent after-effects on unemployment. Our analysis suggests that the rise in EU unemployment in the early 1990s can be attributed largely to this source.

This investigation of the relative importance of long-run shifts versus lagged adjustments has far-reaching policy implications. It is often observed that, over the past three decades, the variations of European unemployment from one business cycle to the next (peak to peak, or trough to trough) have characteristically been larger than the variations within each business cycle (peak to trough). ${ }^{3}$ If these medium-term movements in European unemployment are attributed largely to changes in the long-run labor market equilibrium, then policy makers should concentrate on policies (such as changes in the duration and size of unemployment benefits or changes in interest rates) that influence this long-run equilibrium. On the other hand, if a significant share of the medium-term unemployment movements are attributed to intertemporal adjustments of European labor markets, then policy makers should also focus on measures (such as changes in job security

\footnotetext{
${ }^{3}$ See, for example, Layard, Nickell and Jackman (1991).
} 
legislation to influence firing costs, or job counselling measures to influence hiring costs) that affect the lagged adjustment processes and thereby improve labor market more flexibility in the aftermath of shocks.

Even when these two approaches are concerned with the same policy measures, they focus attention on different attributes of these measures. For instance, changes in job security legislation (e.g. reductions in legislated firing costs) may affect both the long-run equilibrium unemployment rate and the lagged adjustment processes leading to that equilibrium. But whereas the effect of firing costs on the long-run unemployment equilibrium are generally ambiguous, ${ }^{4}$ the influence of these costs on the lagged adjustment processes are usually quite predictable, e.g. a fall in firing costs generally reduces employment inertia.

On these accounts, how we interpret the medium-term movements in unemployment is of far-reaching importance. Although questions of policy design lie outside the scope of this paper, the potential policy implications provide an underlying motivation for our analysis.

The paper is organized as follows. Section 2 summarizes the underlying concepts and ideas. Section 3 presents the empirical model and discusses the related econometric issues. Sections 4 describes our results. Section 5 relates our results to the standard single-equation analyses of unemployment. Section 6 concludes.

\section{Underlying Concepts and Ideas}

We estimate a structural vector autoregressive distributed lag model for the EU countries:

$$
\mathbf{A}(L) \mathbf{y}_{t}=\mathbf{B}(L) \mathbf{x}_{t}+\varepsilon_{t}
$$

where $L$ is the lag operator, $\mathbf{y}_{t}$ is a vector of endogenous variables, $\mathbf{x}_{t}$ is a vector of exogenous variables (including deterministic trends), $\boldsymbol{\varepsilon}_{t}$ is a vector of identically independently distributed error terms, $\mathbf{A}$ and $\mathbf{B}$ are coefficient matrices, and ${ }^{5}$

$$
\mathbf{A}(L)=\mathbf{A}_{0}-\mathbf{A}_{1} L-\ldots-\mathbf{A}_{p} L^{p}, \mathbf{B}(L)=\mathbf{B}_{0}+\mathbf{B}_{1} L+\ldots+\mathbf{B}_{q} L^{q} .
$$

\footnotetext{
${ }^{4}$ See, for example, Bentolila and Saint-Paul (1994), Bertola (1990), and Diaz and Snower (1996).

${ }^{5}$ The dynamic system (2.1) is stable if, for given values of the exogenous variables, all the roots of the determinantal equation
}

$$
\left|\mathbf{A}_{0}-\mathbf{A}_{1} L-\ldots-\mathbf{A}_{p} L^{p}\right|=0
$$

lie outside the unit circle. Note that the estimated equations in Section 3 below satisfy this condition. 
The endogenous variables of our system are employment $\left(n_{t}\right)$, the labor force $\left(l_{t}\right)$, the real wage $\left(w_{t}\right)$, and output $\left(q_{t}\right)$. All variables are national aggregates and all are in logarithms. Thus the equation system (2.1) consists of four equations:

1. the employment equation describes labor demand;

2. the labor force equation describes labor supply;

3. the wage equation indicates how real wages are determined (e.g. through bargaining, efficiency wage considerations, union pressure, etc.);

4. the output equation is a production function; and

5. since all above variables are in logs, the unemployment rate (not in logs) is ${ }^{6}$

$$
u_{t}=l_{t}-n_{t}
$$

Substituting the estimated equations (2.1) into (2.2), and further algebraic manipulation, leads to the following fitted "reduced form" unemployment rate equation: ${ }^{7}$

$$
u_{t}=\sum_{j=1}^{I} \phi_{j} u_{t-j}+\sum_{j=0}^{J} \boldsymbol{\theta}_{j}^{\prime} \mathbf{x}_{t-j}
$$

where the autoregressive parameters $\phi$ and the vectors $\boldsymbol{\theta}$ of the coefficients of the exogenous variables are functions of the estimated structural parameters of (2.1).

Next, we decompose the exogenous variables into their temporary and permanent components: $\mathbf{x}_{t}=\mathbf{v}_{t}+\mathbf{z}_{t}$, where $\mathbf{v}_{t}$ is a vector of the temporary components and $\mathbf{z}_{t}$ is a vector of the permanent components. (The nature of this decomposition will be described in Section 4.) We thus obtain the following unemployment equation:

$$
u_{t}=\sum_{j=1}^{I} \phi_{j} u_{t-j}+\sum_{j=0}^{J} \boldsymbol{\theta}_{j}^{\prime} \mathbf{v}_{t-j}+\sum_{j=0}^{J} \boldsymbol{\theta}_{j}^{\prime} \mathbf{z}_{t-j} .
$$

\footnotetext{
${ }^{6}$ Strictly speaking, this is an approximation.

${ }^{7}$ The stability of the dynamic system (2.1) does not necessarily imply the stability of the reduced form unemployment rate equation (2.2). For the stability of the latter we need all the roots of the polynomial

$$
1-\phi_{1} L-\ldots-\phi_{I} L^{I}=0
$$

to lie outside the unit circle. Note that our estimations in Section 3 below satisfy this condition.
} 


\subsection{Unemployment Repercussions}

In this context, the following unemployment effects may be identified:

- the short-run unemployment effects of the temporary and permanent components: $u_{t}^{S R}(T C)=\boldsymbol{\theta}_{0}^{\prime} \mathbf{v}_{t}$ and $u_{t}^{S R}(P C)=\boldsymbol{\theta}_{0}^{\prime} \mathbf{z}_{t}$, respectively, and

- the long-run unemployment effects of the temporary and permanent components: $u_{t}^{L R}(T C)=\left(1-\sum_{j=1}^{I} \phi_{j}\right)^{-1} \sum_{j=0}^{J} \boldsymbol{\theta}_{j}^{\prime} \mathbf{v}_{t-j}$ and $u_{t}^{L R}(P C)=\left(1-\sum_{j=1}^{I} \phi_{j}\right)^{-1} \sum_{j=0}^{J} \boldsymbol{\theta}_{j}^{\prime} \mathbf{z}_{t-j}$.

The temporary unemployment repercussions (the unemployment trajectory resulting from the temporary components) are the contribution of the temporary components to the unemployment through time:

$$
\mathcal{T}_{t}=\sum_{j=1}^{I} \phi_{j} \mathcal{T}_{t-j}+\sum_{j=0}^{J} \boldsymbol{\theta}_{j}^{\prime} \mathbf{v}_{t-j}
$$

and the corresponding temporary shocks are $\Delta \mathcal{T}_{t}$.

Similarly, the permanent repercussions are the unemployment contribution of the permanent components through time:

$$
\mathcal{P}_{t}=\sum_{j=1}^{I} \phi_{j} \mathcal{P}_{t-j}+\sum_{j=0}^{J} \boldsymbol{\theta}_{j}^{\prime} \mathbf{z}_{t-j}
$$

and the corresponding permanent shocks are $\Delta \mathcal{P}_{t}$.

As equation (2.5) indicates, the temporary repercussion $\left(\mathcal{T}_{t}\right)$ in period $t$ depends on the temporary repercussions $\left(\mathcal{T}_{t-j}\right)$ in the previous $I$ periods and on the short-run unemployment effects of the temporary components $\left(\boldsymbol{\theta}_{j}^{\prime} \mathbf{v}_{t-j}\right)$ in the previous $J$ periods. Suppose that our span of analysis (i.e. our sample period) is from $t=1$ to $t=T$. Then, by the unemployment equation (2.4), the unemployment rate $u_{t}$ may be understood as the sum of three components: (i) the temporary repercussions associated with the temporary components in the sample period, (ii) the permanent repercussions associated with the permanent components in the sample period, and (iii) the temporary and permanent repercussions 
associated with the temporary and permanent components that occurred before the sample period. ${ }^{8}$

Formally, let the temporary repercussions associated with the temporary components in the sample period be denoted by $\left.\mathcal{T}_{t}\right|_{1} \quad t \quad T$. These within-sample temporary repercussions are given by equation (2.5), with the pre-sample values of temporary repercussions $\left(\mathcal{T}_{t-j}\right)$ set equal to zero. Similarly, let the permanent repercussions associated with the permanent components in the sample period be denoted by $\left.\mathcal{P}_{t}\right|_{1} t_{t} T$. These within-sample permanent repercussions are given by the equation (2.6), with the pre-sample values of the permanent repercussions $\left(\mathcal{P}_{t-j}\right)$ set equal to zero. Finally, let the temporary and permanent repercussions associated with the temporary and permanent components that occurred prior to the sample period be denoted by $\left.\mathcal{T} \mathcal{P}_{t}\right|_{t<1}$. Then the estimated unemployment rate may be expressed as

$$
u_{t}=\left.\mathcal{T} \mathcal{P}_{t}\right|_{t<1}+\left.\mathcal{T}_{t}\right|_{1} t_{t} T+\left.\mathcal{P}_{t}\right|_{1 \quad t} \quad T
$$

In empirical analysis, we can of course identify the three right-hand terms separately; what we cannot do identify separately are the temporary and permanent repercussions that generate the the first term $\left(\left.\mathcal{T} \mathcal{P}_{t}\right|_{t<1}\right)$, since we do not know the entire pre-sample history of the temporary and permanent components. Instead, we make a simple assumption. Since the temporary components are interpretted as transient shocks, we expect the lion's share of the first term to be generated by permanent components. So, for simplicity, in the empirical analysis below we will assume that the entire first term can be attributed to permanent components, so that this term may be interpretted as part of the permanent repercussions.

\footnotetext{
${ }^{8}$ To see this straightforwardly, consider the simple case where the unemployment rate equation (2.4) is of first order and there is only one temporary component and one permanent component:

$$
u_{t}=\phi u_{t-1}+\theta z_{t}+\theta v_{t}, t=1,2, \ldots, T
$$

Using backward substitution, we can express the unemployment rate in terms of its pre-sample value $u_{0}$ :

$$
u_{t}=\phi^{t} u_{0}+\theta \sum_{j=0}^{j=t-1} \phi^{j} z_{t}+\theta \sum_{j=0}^{j=t-1} \phi^{j} v_{t} .
$$

Here the first right-side term stands for the temporary and permanent repercussions associated with the temporary and permanent components occurring before the sample period (embodied in the initial unemployment rate $u_{0}$ ); the second term stands for the permanent repercussions associated with the permanent components in the sample period; and the third term stands for the temporary repercussions associated with the temporary components in the sample period.
} 


\subsection{The Frictionless Equilibrium Unemployment Rate}

The frictionless equilibrium unemployment rate is the value that the unemployment rate would achieve once all the lagged adjustment processes have worked themselves out, given the exogenous variables. Thus the FEU is the sum of the long-run unemployment effects of the temporary and permanent components:

$$
F E U_{t} \equiv u_{t}^{L R}(T C)+u_{t}^{L R}(P C)=\left(1-\sum_{j=1}^{I} \phi_{j}\right)^{-1}\left(\sum_{j=0}^{J} \boldsymbol{\theta}_{j}^{\prime} \mathbf{v}_{t-j}+\sum_{j=0}^{J} \boldsymbol{\theta}_{j}^{\prime} \mathbf{z}_{t-j}\right) .
$$

As noted, the more quickly the lagged adjustment processes work themselves out, the closer the temporary repercussions approximate the long-run unemployment effects of the TCs and the closer the permanent repercussions approximate the long-run unemployment effects of the PCs. Consequently, the closer the estimated unemployment rates come to the frictionless equilibrium unemployment rates through time.

\subsection{A Simple Example}

Suppose, for simplicity, that the unemployment equation is a first-order autoregression with one temporary component, $v_{t}$, and one permanent component, $z_{t}$ :

$$
u_{t}=\phi u_{t-1}+\theta x_{t}=\phi u_{t-1}+\theta v_{t}+\theta z_{t}
$$

where $0<\phi<1$. This equation, in period $t=0$, is illustrated by the unemployment dynamics line $U D_{0}$ in Figure 2.

Consider the sequence of unemployment responses associated with a change in the temporary component, viz., a single one-off unit shock in the form of a unit rise at period $t: v_{t}=1$. Thus the short-run (immediate impact) unemployment effect is $\mathcal{T}_{t}=\theta$, as illustrated in Figure 2 by the rise in the unemployment dynamics line from $U D_{0}$ to $U D_{1}$ and the corresponding movement of the unemployment equilibrium point from $E_{0}$ to $E_{1}$. Since the shock is temporary, it disappears after period $t: v_{t+j}=0, j \geq 1$. Thus the unemployment dynamics line in Figure 2 returns to $U D_{0}$ for $t>1$. 


\section{Figure 2: Effects of Temporary and Permanent Shocks}

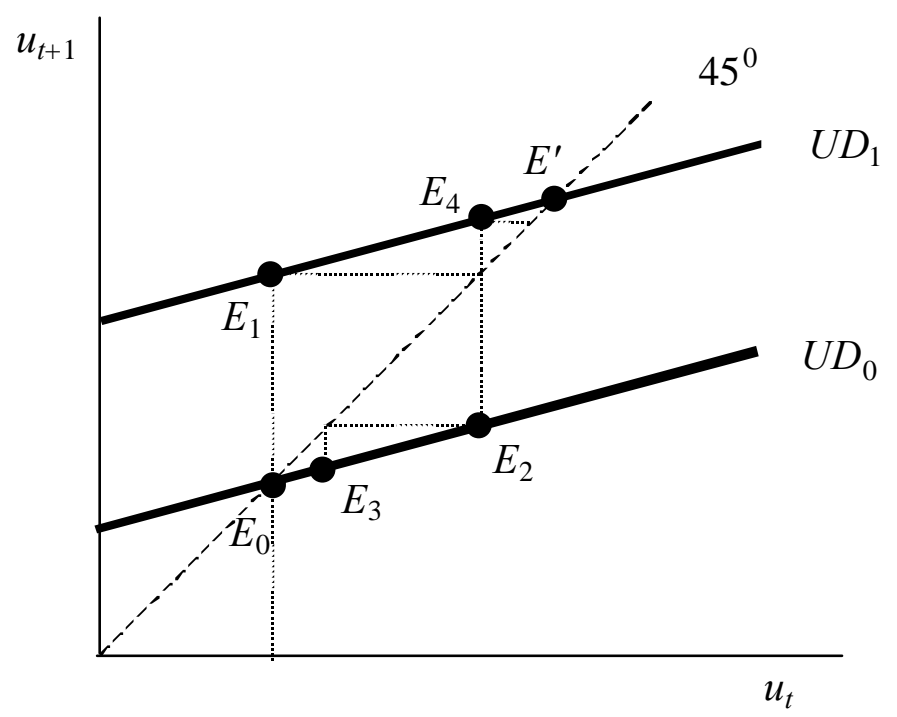

Nevertheless, the unemployment effects of the temporary shock persist through time. In period $t+1$ the unemployment equilibrium point shifts to $E_{2}$ in the figure, so that the change in the temporary unemployment repercussion in period $t+1$ is $\mathcal{T}_{t+1}=\phi \theta$. Next, in period $t+2$ the unemployment equilibrium point moves on to $E_{3}$, and the corresponding change in the temporary unemployment repercussion is $\mathcal{T}_{t+2}=\phi^{2} \theta$, and so on. Thus the entire sequence of unemployment changes resulting from the temporary shock, from period $t+1$ onwards, is $\mathcal{T}_{t+j}=\phi^{j} \theta, j \geq$ 1.

The unemployment repercussions associated with a permanent shock are quite different. Let the shock be a permanent unit rise, beginning in period $t: z_{t+j}=$ $1, j \geq 0$. Now the unemployment dynamics line moves from $U D_{0}$ to $U D_{1}$, as shown in Figure 2, and remains there for ever. The short-run (immediate impact) unemployment effect is $\mathcal{P}_{t}=\theta$, as the unemployment equilibrium moves from point $E_{0}$ to $E_{1}$. In the following period, the equilibrium point moves to $E_{4}$, and the associated unemployment response to the permanent shock can be expressed as $\mathcal{P}_{t+1} \equiv \theta+\theta \phi$, i.e. the sum of the effects of the permanent shock on unemployment in periods $t$ and $t+1$. As this process continues through time, the unemployment rate gradually approaches its new equilibrium point $E^{\prime}$. The unemployment effect of a unitary permanent shock $k$ periods after its occurrence is $\mathcal{P}_{t+k} \equiv \theta \sum_{j=0}^{k} \phi^{j}$.

This simple example shows why it is so important to distinguish between the unemployment effects of the temporary and permanent components. The greater the persistence parameter $\phi$ (i.e. the steeper the unemployment dynamics line), the more persistent are the after-effects of the temporary shock, but the longer 
it takes for the full (long-run) effects of the permanent shock to manifest themselves. It can be shown, however, that this positive relation between the degree of persistence from temporary shocks and the degree of inertia from permanent shocks does not hold invariably for higher-order unemployment autoregressions. In general, more persistence may be associated with more inertia or more overshooting (the opposite of inertia), depending on the values of the autoregressive parameters. So temporary and permanent shocks have quite different dynamic implications and thus need to be studied separately.

It is on this account that we decompose the time series of the exogenous variable $\left(x_{t}, x_{t+1}, x_{t+2}, \ldots\right)$ into a time series of the temporary component $\left(v_{t}, v_{t+1}, v_{t+2}, \ldots\right)$ and a time series of the permanent component $\left(z_{t}, z_{t+1}, z_{t+2}, \ldots\right)$. We view the time series of the temporary component as a sequence of one-off shocks: the shock $\left(v_{t}, 0,0,0, \ldots\right)$, followed by the shock $\left(0, v_{t+1}, 0,0,0, \ldots\right)$, followed by the shock $\left(0,0, v_{t+2}, 0,0,0, \ldots\right)$, and so on. This is illustrated in Figure 3a.

Figure 3a: A Temporary Component Time Series

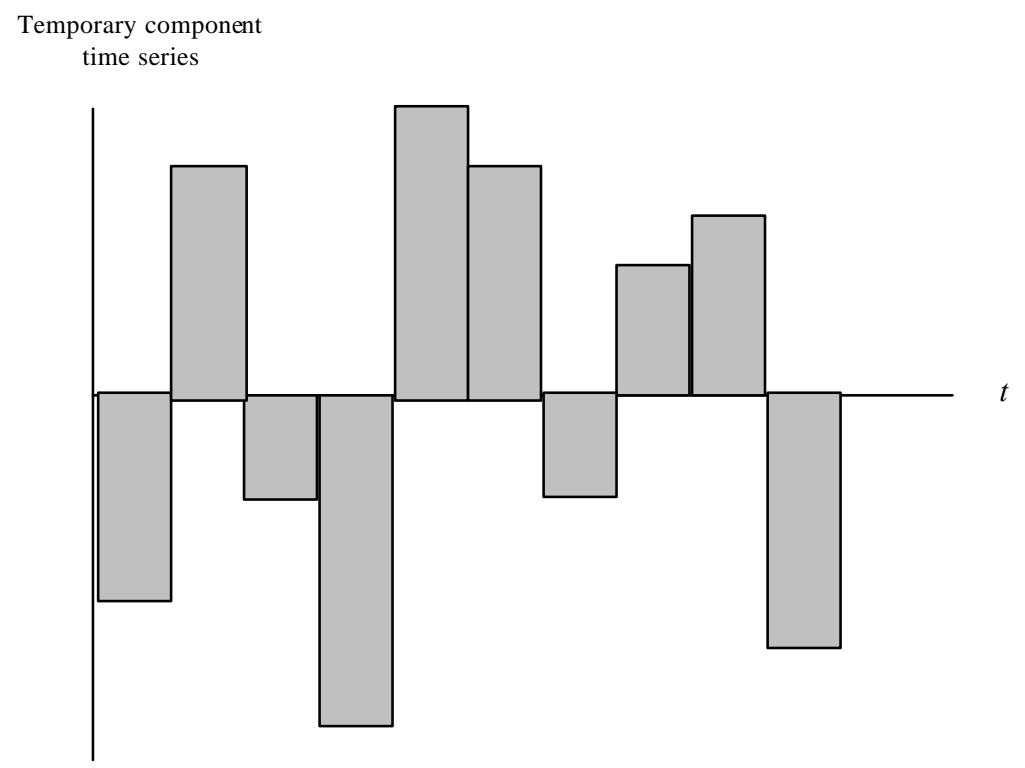

The infinite moving average representation (I.M.A.) of the unemployment equation (2.8) is

$$
u_{t}=\theta\left(v_{t}+z_{t}\right)+\theta \phi\left(v_{t-1}+z_{t-1}\right)+\theta \phi^{2}\left(v_{t-2}+z_{t-2}\right)+\ldots \ldots
$$


Thus the temporary unemployment repercussions $\left(\mathcal{T}_{t+k}\right)$ through time are given by

$$
\begin{aligned}
\mathcal{T}_{t} & =\theta v_{t} \\
\mathcal{T}_{t+1} & =\theta v_{t+1}+\theta \phi v_{t} \\
\mathcal{T}_{t+2} & =\theta v_{t+2}+\theta \phi v_{t+1}+\theta \phi^{2} v_{t} \\
\mathcal{T}_{t+k} & =\theta \sum_{j=0}^{k} \phi^{j} v_{t+k-j} .
\end{aligned}
$$

Moreover, we view the time series of the permanent component $\left(z_{t}, z_{t+1}\right.$, $\left.z_{t+2}, \ldots\right)$ as the cumulative sum of permanent shocks through time: the shock $\left(\widetilde{z}_{t}, \widetilde{z}_{t}, \widetilde{z}_{t}, \ldots\right)$, followed by the shock $\left(0, \widetilde{z}_{t+1}, \widetilde{z}_{t+1}, \widetilde{z}_{t+1}, \ldots\right)$, followed by the shock $\left(0,0, \widetilde{z}_{t+2}, \widetilde{z}_{t+2}, \widetilde{z}_{t+2}, \ldots\right)$, and so on. The cumulative sum of these shocks is $\left(z_{t}, z_{t+1}, z_{t+2}, \ldots\right)=\left(\widetilde{z}_{t},\left(\widetilde{z}_{t}+\widetilde{z}_{t+1}\right),\left(\widetilde{z}_{t}+\widetilde{z}_{t+1}+\widetilde{z}_{t+2}\right), \ldots\right)$, as illustrated in Figure 3b. ${ }^{9}$

Figure 3b: A Permanent Component Time Series

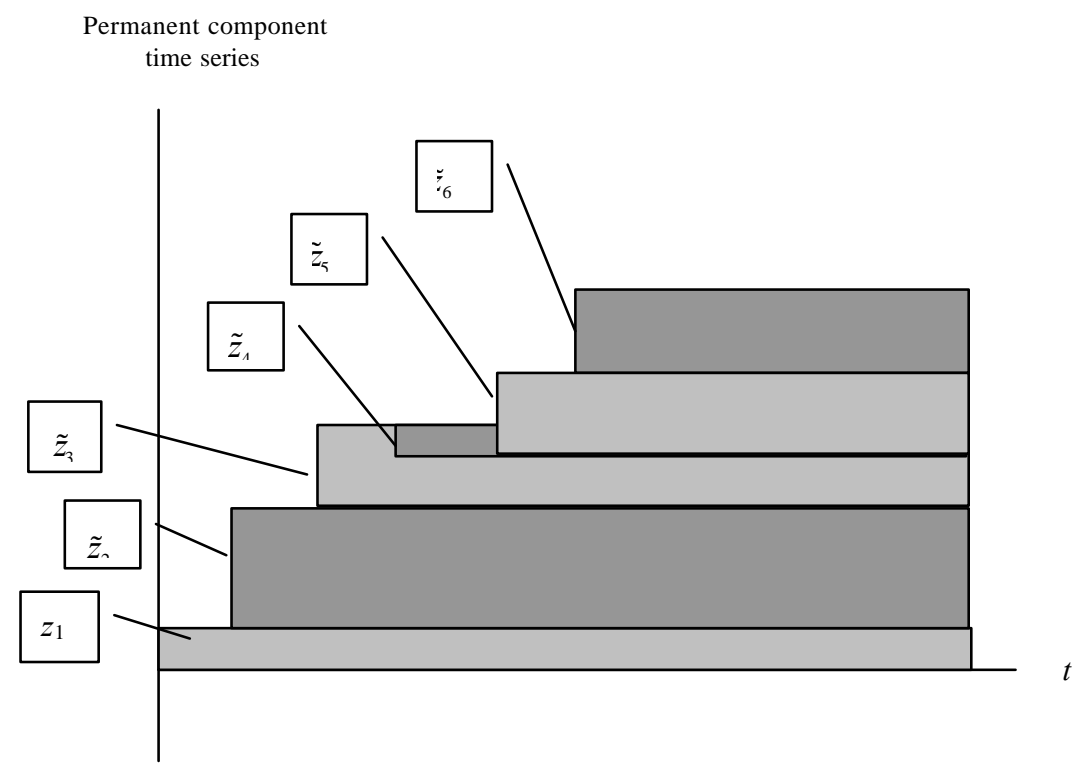

\footnotetext{
${ }^{9}$ Note that in the figure the first three shocks are positive shocks, the third is negative, and the last two are positive.
} 
Thus, the permanent repercussions (the unemployment trajectory resulting from the permanent components) are given by

$$
\begin{aligned}
\mathcal{P}_{t} & =\left(\theta \widetilde{z}_{t}\right) \\
\mathcal{P}_{t+1} & =\theta \widetilde{z}_{t}+\theta \widetilde{z}_{t+1}+\theta \phi \widetilde{z}_{t}=\left(\theta \widetilde{z}_{t}+\theta \phi \widetilde{z}_{t}\right)+\left[\theta \widetilde{z}_{t+1}\right] \\
\mathcal{P}_{t+2} & =\theta \widetilde{z}_{t}+\theta \widetilde{z}_{t+1}+\theta \widetilde{z}_{t+2}+\theta \phi \widetilde{z}_{t}+\theta \phi \widetilde{z}_{t+1}+\theta \phi^{2} \widetilde{z}_{t} \\
& =\left(\theta \widetilde{z}_{t}+\theta \phi \widetilde{z}_{t}+\theta \widetilde{z}_{t}\right)+\left[\theta \widetilde{z}_{t+1}+\theta \phi \widetilde{z}_{t+1}\right]+\theta \widetilde{z}_{t+2}
\end{aligned}
$$

and so on. ${ }^{10}$ In short, the permanent component ${ }^{11}$ at time $t+k$ is $\mathcal{P}_{t+k}=$ $\theta \sum_{j=0}^{k} \phi^{j} z_{t+k-j}$.

\section{The Empirical Model and Econometric Issues}

We have estimated a panel data model for the EU countries covering the last three decades. This model has two features that differentiate it from the standard ones used in pooled estimation: (i) it is a structural model, rather than merely a standard reduced-form equation and (ii) it is dynamic, rather than static.

In this section we first examine the appropriate methodology for such dynamic panel data estimation, and then describe the results of our estimation.

\subsection{Dynamic Panels}

The advantages of using panel data sets for economic research are numerous and well documented in the literature. ${ }^{12}$ For example, the pooling of observations on a cross section of countries over several time periods can increase the efficiency of econometric estimates and can provide a better understanding of the adjustment mechanisms in dynamic relationships. In recent years, dynamic panel data and nonstationary panel time series models have attracted a lot of attention. As a result, the study of the asymptotics of macro panels with large $N$ (number of units, e.g. countries) and large $T$ (length of the time series) has become the focus of panel data econometrics. Banerjee (1999) and Baltagi and Kao (2000), and Smith (2000) provide an overview of the above topics and survey the developments in this technical and rapidly growing literature.

\footnotetext{
${ }^{10}$ Observe that the terms in parentheses in the above equations show the unemployment effects at each point in time of the permanent shock that occurs at period $t$. Similarly, the terms in square brackets are the unemployment responses to the permanent shock that occurs at period $t+1$.

${ }^{11}$ The reason that we do not refer to initial values in this illustration is because we assume that we can observe the whole history of exogenous variables.

${ }^{12}$ See, for example, Hsiao (1986) and Baltagi (1995) for a detailed exposition of stationary panel data estimation.
} 


\subsubsection{Panel Unit Root Tests}

During the past several years testing for the order of integration in time series has been common practice in applied economic research. It is by now well known that the popular Dickey-Fuller (DF), augmented DF (ADF), and Phillips-Perron $(\mathrm{PP})$ unit root tests have limited power in distinguishing the null of a unit root from stationary alternatives with highly persistent deviations from equilibrium. Although testing for unit roots in panels is recent, ${ }^{13}$ it is generally accepted that the use of pooled cross-section time series data can generate more powerful unit root tests.

In our empirical work we employ the simple statistic proposed by Maddala and $\mathrm{Wu}(1999)$ to test for panel unit roots. This is an exact nonparametric test based on Fisher (1932):

$$
\lambda=-2 \sum_{i=1}^{N} \ln \pi_{i} \sim \chi^{2}(2 N),
$$

where $\pi_{i}$ is the probability value of the ADF unit root test for the $i$ th unit (country). The Fisher test has several attractive features. First, since it combines the significance of $N$ different independent unit root statistics, it does not restrict the autoregressive parameter to be homogeneous across $i$ under the alternative of stationarity. Second, the choice of the lag length and of the inclusion of a time trend in the individual $\mathrm{ADF}$ regressions can be determined separately for each country. Third, the sample sizes of the individual ADF tests can differ according to data availability for each cross-section. Finally, it should be noted that the Fisher statistic can be used with any type of unit root test. Maddala and $\mathrm{Wu}$ (1999), using Monte Carlo simulations, conclude that the Fisher test outperforms both the Levin and Lin (1993) and the Im et al (1997) tests ${ }^{14}$.

\footnotetext{
${ }^{13}$ See, for example, Levin and Lin (LL) (1993), Im, Pesaran and Shin (1997), Harris and Tzavalis (1999), Maddala and Wu (1999). Note that the asymptotic properties of tests and estimators proposed for nonstationary panels depend on how $N$ (the number of cross-section units) and $T$ (the length of the time series) tend to infinity, see Phillips and Moon (1999).

${ }^{14} \mathrm{LL}$ proposed asymptotic panel unit root tests which are based on pooled regressions. The major criticism against the LL tests is that, under the alternative of stationarity, the autoregressive coefficient is the same across all units (i.e. $H_{1}: \rho_{1}=\rho_{2}=\ldots=\rho_{N}=\rho<0$ ).

This restrictive assumption is relaxed in the asymptotic test proposed by Im, Pesaran and Shin (IPS) (1997). Like the Fisher test, and in contrast to the LL tests, the IPS test is based on the individual ADF regressions for each of the $N$ cross-section units. While the Fisher test uses the probability values of the individual ADF tests, the IPS uses their test statistics. Compared to the Fisher test, the disadvantage of the IPS test is that it implicitly assumes the same $T$ for all countries and the same lag length for all the individual ADF regressions.
} 


\subsubsection{Estimation of Dynamic Panels}

We estimate the short-run and long-run parameters of behavioral relationships by using dynamic panel data models, i.e. models characterized by the presence of lagged dependent variables among the regressors, such as ${ }^{15}$

$$
y_{i t}=\alpha y_{i, t-1}+\beta^{\prime} x_{i t}+\varepsilon_{i t},
$$

where $\alpha$ is a scalar, $\beta$ is a $K \times 1$ vector of constants, and $x_{i t}$ is a $K \times 1$ vector of explanatory variables. The disturbances are assumed to follow a one-way error component model ${ }^{16}$

$$
\varepsilon_{i t}=\mu_{i}+\nu_{i t}, i=1, \ldots, N, t=1, \ldots, T,
$$

where $\nu_{i t} \sim$ iid $\left(0, \sigma_{\nu}^{2}\right)$ with $\operatorname{Cov}\left(\varepsilon_{i t}, \varepsilon_{j t}\right)=0$, for $i \neq j$. The scalar $\mu_{i}$ represents the effects that are specific to the $i$ th unit and are assumed to remain constant over time. In this case, equations (3.2)-(3.3) give the fixed-effects (FE) model: slope coefficients and variances are identical across groups and only intercepts are allowed to vary. Note that the FE estimator ${ }^{17}$ is the most common estimator for dynamic panels.

In homogenous dynamic panels (i.e. models with constant slopes: $\alpha_{i}=\alpha$, and $\beta_{i}^{\prime}=\beta$ ) the FE estimator is consistent as $T \rightarrow \infty$, for fixed $N .{ }^{18}$ However, pooling the data in dynamic heterogeneous panels (i.e. when $\alpha_{i} \neq \alpha$, and $\beta_{i}^{\prime} \neq \beta$ ) leads to inconsistent estimators even for large $N$ and $T$. This inconsistency ${ }^{19}$ was demonstrated by Pesaran and Smith (1995) (extended in Im, Pesaran and Smith (1996)) who advocated the use of group-mean estimators instead of pooled ones.

The degree of heterogeneity is important in deciding whether to pool or not. Given that the hypothesis of homogeneity will almost always be rejected ${ }^{20}$ when the sample size is sufficiently large and the significance level fixed, Smith (2000) suggests to use a model selection criterion to decide on the poolability of the

\footnotetext{
${ }^{15}$ Although our estimations contain both the first and second lags of the dependent variable, for expositional simplicity we ignore higher order lags in equation (3.2).

${ }^{16}$ Again, we do not present the two-way error component model for expositional simplicity. However, we used time-specific effects $\left(\lambda_{t}\right)$ in our estimations and for some of our structural equations these appear in the form of a time trend.

${ }^{17}$ The fixed-effects estimator is also known as the least squares dummy variables (LSDV) estimator, or the within-group or the analysis of covariance estimator.

${ }^{18}$ Kiviet (1995) showed that the bias of the FE estimator in a dynamic model of panel data has an approximation error of $O\left(N^{-1} T^{-3 / 2}\right)$. Therefore, the FE estimator is consistent only as $T \rightarrow \infty$, while it is biased and inconsistent when $N$ is large and $T$ is fixed.

${ }^{19}$ Robertson and Symons (1992) were the first to notice the bias obtained when the true model is static and heterogenous and the estimated one is dynamic and homogenous.

${ }^{20}$ This is also noted by Baltagi and Griffin (1997): “...even though formal tests for hom ogeneity are rejected as is the case here, like most researchers we proceed to estimate pooled models".
} 
data. We use the Schwarz Information Criterion (SIC) which penalizes overparameterization more heavily than tests at the conventional significance levels.

Baltagi and Griffin (1997) compare the performance of a large number of homogenous and heterogeneous estimators in the context of dynamic demand for gasoline. The cross-section and time dimensions in the Baltagi and Griffin (BG) study are very similar to the dimensions of the panel data used in this paper: they use a panel data set for 18 OECD countries with annual data covering the period 1960-1990. BG find that the individual country estimates (both OLS and 2SLS) exhibit substantial variability, suggesting that "the individual country estimates are highly unstable and unreliable," and they find that pooled estimators provide more plausible estimates. BG justify the use of pooled estimators by concluding that "the efficiency gains from pooling appear to more than offset the biases due to intercountry heterogeneities". ${ }^{21}$

Given the above arguments by BG and the support for the homogeneity hypothesis by the Schwarz selection criterion (see the section below), we proceed by estimating our dynamic panel using the fixed effects estimator.

\subsection{The EU model}

\subsubsection{The Data}

Eleven out of the fifteen EU countries have been included in our empirical model: Austria, Belgium, Denmark, Germany, Finland, France, Italy, Netherlands, Spain, Sweden and the United Kingdom. The reason for excluding the remaining four countries - Greece, Ireland, Luxembourg and Portugal - is the lack of data in some crucial variables (such as the capital stock) or reduced data availability in others (such as the long-run interest rates). We use annual data and the estimation period is $1970-1999$.

The data source is the OECD, and the definition of the variables used in the estimation is provided in Table 1.

\section{Insert table 1}

\footnotetext{
${ }^{21} \mathrm{BG}$ also find that "the gains from correcting for possible endogeneity in the lagged dependent variable are disappointing as the 2SLS estimators performed worse than their counterparts assuming all variables are exogenous". In particular, they note that standard pooled estimators give larger long-run elasticities (i.e. larger autoregressive parameters) than their 2SLS counterparts. Although they acknowledge the role of bias, they suspect that low autoregressive coefficients are simply due to poor instruments: "Current and lagged values of the exogenous variables produce instruments that do not closely explain the lagged dependent variable."
} 


\subsubsection{Panel Unit Roots}

We use the Fisher statistic (3.1) proposed by Maddala and Wu (1999) to test for panel unit roots. As noted, the Fisher test is based on the ADF regressions for the individual countries. The order of augmentation and the sample size are allowed to vary in the individual unit root tests, and a time trend is included when necessary. Table 2 reports the Fisher statistics for all the variables used in our structural equations. The null hypothesis is that the time series has been generated by an $I$ (1) stochastic process, and the test follows a chi-square distribution with 22 degrees of freedom (the $5 \%$ critical value is approximately 34 ). Note that all the panel unit root test statistics are greater than the critical value, so the null of a unit root can be rejected at the $5 \%$ significance level. Thus we can proceed with stationary panel data estimation techniques.

Insert table 2

\subsubsection{The multi-equation system}

As noted, our empirical model comprises four estimated equations - the employment, labor supply, wage setting, and production equations - plus the definition of the unemployment rate.

In the employment equation, labor demand depends negatively on the real wage and the real interest rate, and positively both on the level and the growth rate of capital stock. Labor demand also depends positively on competitiveness (the ratio of the import price to the GDP deflator); this influence could operate through firms' costs of imported inputs. ${ }^{22}$

\section{Insert table 3}

The wage equation is also plausible, showing the real wage to depend negatively on the unemployment rate and indirect taxes, and positively on productivity and social security benefits.

\section{Insert table 4}

In the labor supply equation, the size of the labor force depends negatively on the level and growth of the unemployment rate (thereby exhibiting the common discouraged-worker effects) and positively on the working-age population. The

\footnotetext{
${ }^{22}$ Note that labor demand also depends positively on the time trend, which is meant to capture labor-augmenting technological change.
} 
long-run elasticity of labor supply with respect to the working-age population is restricted to unity. ${ }^{23}$

\section{Insert table 5}

Finally, the estimated production function is standard, with output depending positively on employment, the capital stock, and a time trend. ${ }^{24}$

\section{Insert table 6}

It is important to point out an unconventional feature of this model. Although it is natural to let labor demand and labor supply depend on trended variables such as the capital stock and working-age population, the resulting system of estimated equations implies a reduced-form unemployment equation in which the unemployment rate depends on these trended variables as well. Since the unemployment rate is untrended in practice (viz., it does not approach zero or 100 percent with the passage of time), it follows that the long-run growth rates of the trended variables must be such that the linear combination of these variables in the reduced-form unemployment equation is untrended.

Most conventional empirical labor market models, by contrast, are specified in such as way that in the resulting reduced-form unemployment equation, the longrun unemployment rate only depends on stationary variables. ${ }^{25}$ This approach reflects what may be call the "unemployment invariance hypothesis," according to which the behavior of the labor market ensures that the long-run unemployment is invariant with respect to the capital stock, productivity, the labor force, and other trended variables. The restrictions that this hy pothesis imposes on empirical models are usually rejected by the data, but they are imposed nevertheless, with the common argument that the long-run unemployment rate, being stationary, cannot depend on non-stationary variables. But this argument is not correct. It presupposes that the labor market, by itself, contains all the equilibrating mechanisms that guarantee unemployment invariance. But all that is required is just that all the markets in the general equilibrium system perform such equilibration. Accordingly, if the labor market does not perform ensure unemployment invariance on its own, but performs this function in conjunction with the other markets in the economy, then it can be shown that the long-run unemployment rate will

\footnotetext{
${ }^{23}$ The Wald test could not reject this restriction at the conventional $5 \%$ significance level. Note also that the real wage has a weak contractionary influence on labor supply, suggesting a slightly dominant income effect.

${ }^{24}$ The production function also captures the influence of raw materials via the oil price.

${ }^{25}$ See, for example, Layard, Nickell, and Jackman (1991).
} 
depend on non-stationary variables, but the long-run combination of these variables appearing in the reduced-form unemployment equation is stationary. (This argument is made formally in Karanassou and Snower (2002).)

In our estimated system of labor market equations, differences in labor market behavior across countries was captured solely through fixed effects, viz., only differing constants in the estimated equations (but identical coefficients for the exogenous variables and the endogenous regressors). In fact, the Schwarz model selection criterion prefers this fixed-effect model above over heterogeneous models containing individual country time series regressions.

Specifically, we select between each of the pooled models presented in Tables 3-6 and the corresponding individual regressions by using the Schwarz Information Criterion $(S I C) .{ }^{26}$ We compute the model selection criteria as follows:

$$
\begin{gathered}
S I C_{\text {pooled }}=M L L-0.5 k_{\text {pooled }} \log (N T), \\
S I C_{\text {individual }}=\sum_{i=1}^{11} M L L_{i}-N\left[0.5 k_{i} \log (T)\right],
\end{gathered}
$$

where $M L L_{\text {pooled }}, M L L_{i}$ denote the maximum log likelihoods of the pooled model and the $i$ th country time series regression, respectively; $k_{\text {pooled }}$ is the number of parameters estimated in the fixed effects model (i.e. number of explanatory variables plus the 11 country specific effects), and $k_{i}$ is the number of parameters estimated in the individual country time series regression (i.e. number of explanatory variables plus an intercept); $N$ and $T$ denote the number of countries and estimation period, respectively.

The above criteria are given in Table 7. The fixed effects model is preferred for all our four behavioral equations: labor demand, wage setting, labor force, and production function. This means that our stationary dynamic panel is homogenous and the fixed effects estimator is consistent.

\section{Insert table 7}

Despite this strong restriction of capturing cross-country differences only by the constants in the estimated equations, our estimated system generates a fitted unemployment rate that tracks the actual unemployment rate remarkably well. This is the case not only at the EU level, as shown in Figure 4, but also at the country-specific level, as shown in Figures 5.

\footnotetext{
${ }^{26}$ The model that maximizes $S I C$ is preferred.
} 
Figure 4: Actual and fitted unemployment rate.

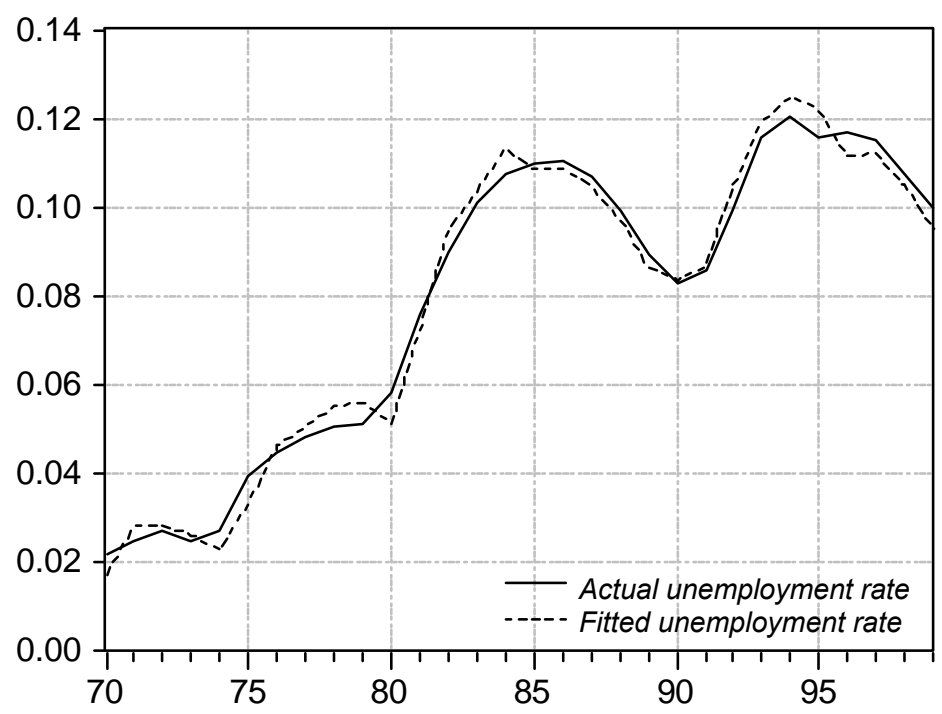

\section{Long-Run Shifts versus Lagged Adjustments}

We now use the estimated model above to examine the degree to which the movements in EU unemployment can be accounted for by shifts in the long-run unemployment equilibrium versus lagged adjustments to that equilibrium. For this purpose, we follow the methodology outlined in Section 2, decomposing the exogenous variables into temporary and permanent components (TCs and PCs), and derive the corresponding temporary and permanent unemployment repercussions $\left(\mathcal{T}_{t}\right.$ and $\left.\mathcal{P}_{t}\right)$. We then decompose these repercussions into their long-run unemployment effects and the associated dynamic adjustments.

\subsection{Temporary and Permanent Unemployment Repercussions}

The exogenous variables in our estimated model may be divided into two groups:

- stationary variables: competitiveness $(c)$, indirect taxes $(\tau)$, oil prices $(o)$ and real interest rates $(r)$,

- trended variables: social security benefits $(b)$, capital stock $(k)$ and workingage population $(\zeta)$. 
Figure 5: Actual and fitted unemployment rates for individual EU countries
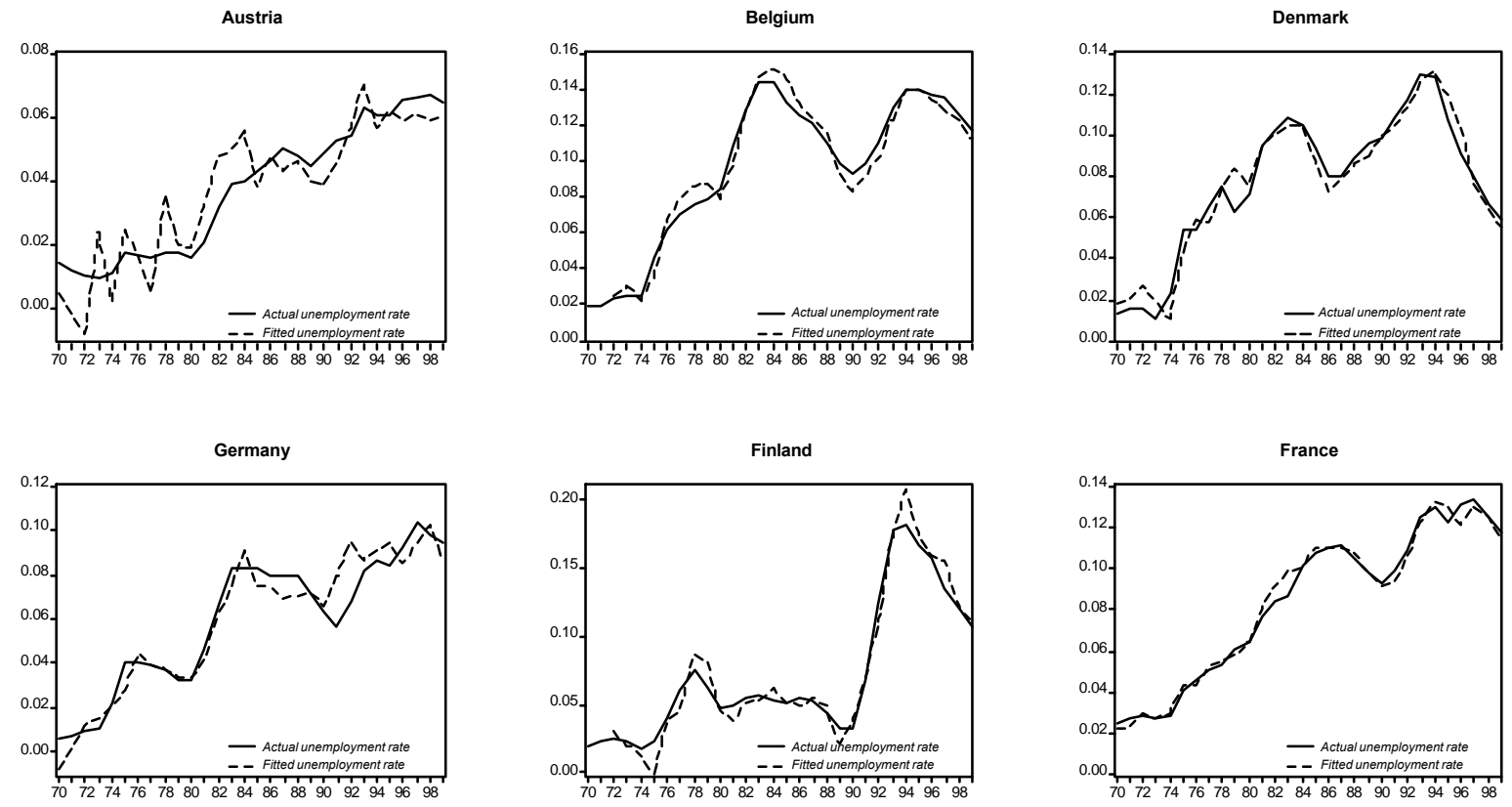

Italy
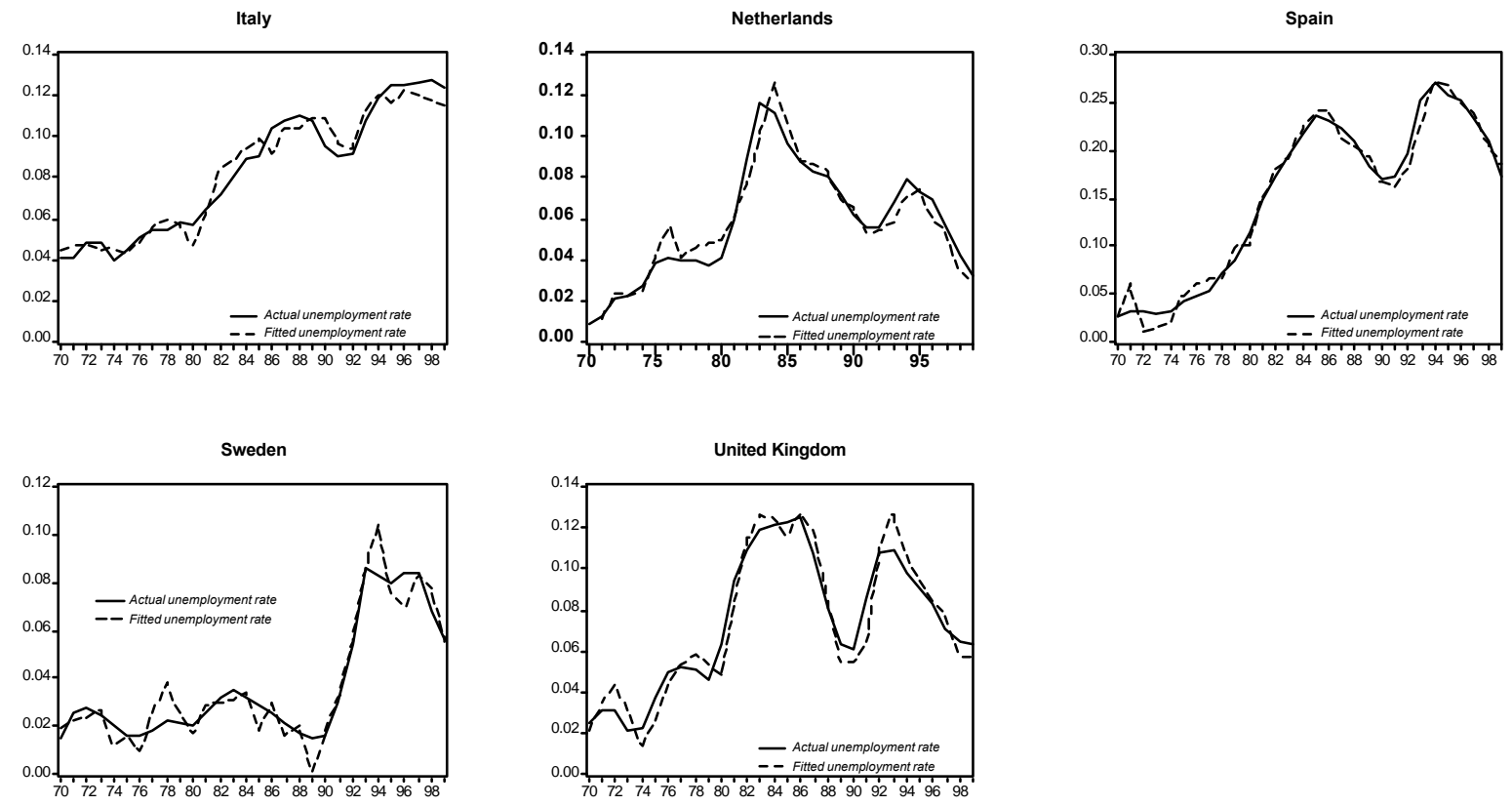

For the first group of variables, the permanent components are identified as the sample means, leaving the temporary components as the random variations 
around these means (i.e. the actual values of the variables minus the means). For the second group of variables, by contrast, the permanent components are identified as the Hodrick-Prescott filtered series, and the temporary components are the variations around these series (i.e. the actual values of the variables minus the filtered series). These decompositions are simple, transparent and intuitively plausible.

The simplest way of measuring the permanent components is through their short-run unemployment effects, $u_{t}^{S R}(P C)$. In this way, all the permanent components can be measured on a common scale, in a way immediately relevant to unemployment. These short-run (impact) effects are given in Figure 6. With reference to the unemployment equation (2.4) $\left(u_{t}=\sum_{j=1}^{I} \phi_{j} u_{t-j}+\sum_{j=0}^{J} \boldsymbol{\theta}_{j}^{\prime} \mathbf{v}_{t-j}+\right.$ $\left.\sum_{j=0}^{J} \boldsymbol{\theta}_{j}^{\prime} \mathbf{z}_{t-j}\right)$, the short-run unemployment effect of the permanent components $\mathbf{z}_{t}$ (i.e. the influence of $\mathbf{z}_{t}$ on $u_{t}$, within the same period) is given by $u_{t}^{S R}(P C)=\boldsymbol{\theta}_{0}^{\prime} \mathbf{z}_{t}$. The first line (I) in Figure 6 denotes the constant plus the trend plus the permanent components of the capital stock and the working-age population. The second line (II) adds the permanent components of social security benefits to line I; the third line (III) adds the permanent component of competitiveness to line II; and so on. Observe that each group of exogenous variables makes a significant, and comparably large contribution to the total short-run effects of the permanent components.

Figure 6: Short-run unemployment effects of the permanent components (PCs)

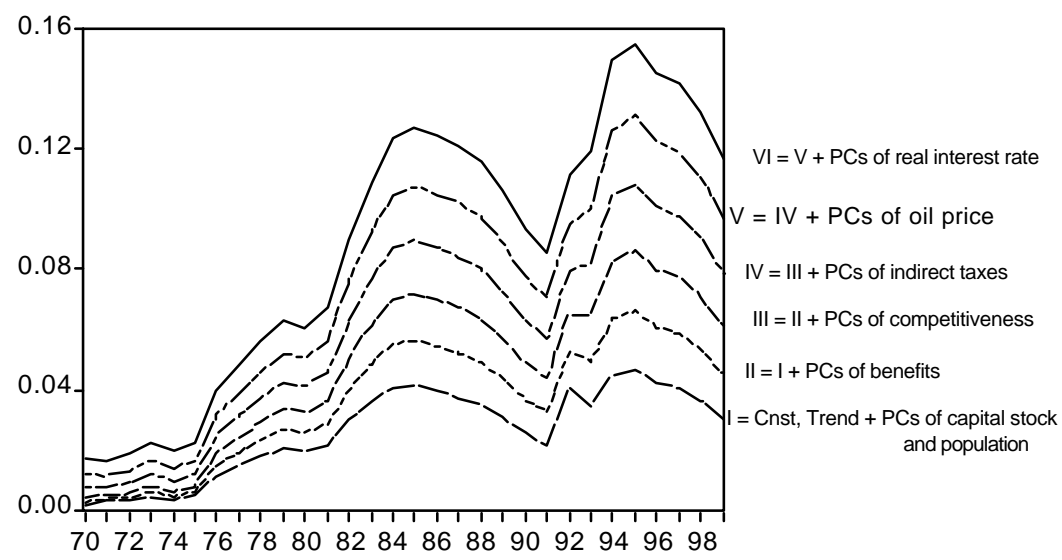

Along the same lines, the short-run unemployment effects of the temporary components $\mathbf{v}_{t}$ on $u_{t}$ are given by $u_{t}^{S R}(T C)=\boldsymbol{\theta}_{0}^{\prime} \mathbf{v}_{t}$, and are presented in Figures $7 \mathrm{a}$ and $7 \mathrm{~b}$. 

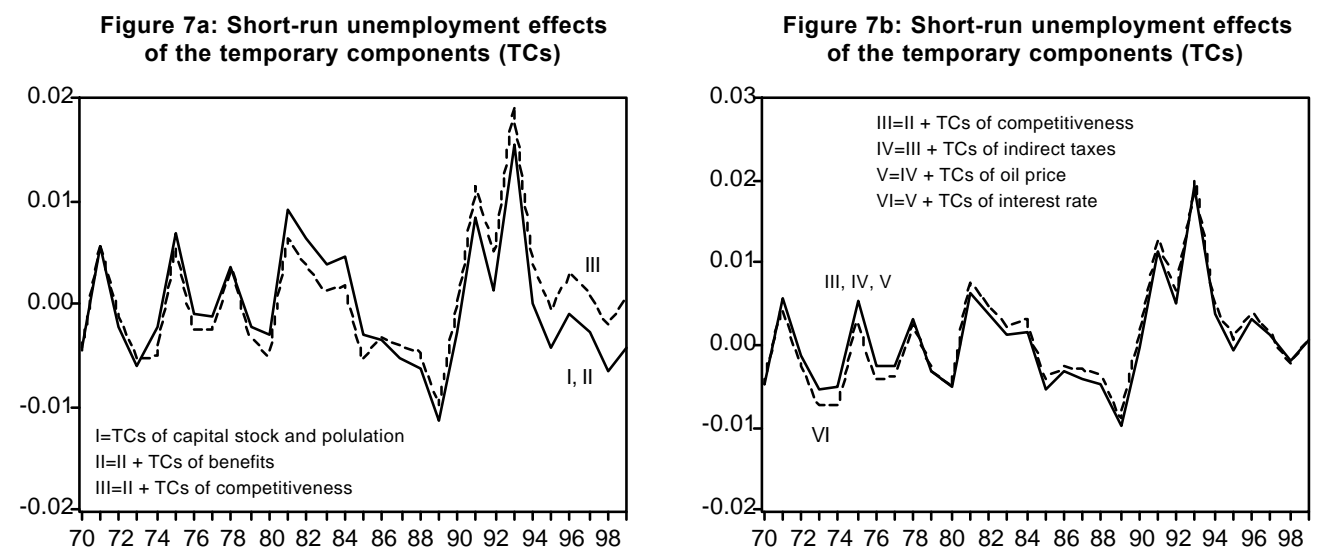

The first line (I) in the figure describes the temporary components of the capital stock and the working-age population; the second line (II) adds the temporary components of social security benefits to line I; and so on. It is important to observe that only the capital stock and population, competitiveness, and the interest rate make a substantial contribution to the total short-run effect of the $T C s$. Hence, since the contribution of social security benefits is very small, and thus the lines I, II are almost identical (and indistinguishable to the naked eye in Fig. 7a). Similarly, since the contributions of indirect taxes and the oil price is small, lines III, IV, and V are also indistinguishable.

As we have seen in Section 1, the unemployment impact effects of the temporary and permanent components are followed by a chain reaction of lagged adjustments. We derive the temporary and permanent unemployment repercussions, given by equations (2.5) and (2.6), as the cumulation through time of these chain reactions for each successive temporary and permanent component, respectively. Specifically, the temporary repercussions are derived by setting the permanent components of the exogenous variables and the pre-sample values of the endogenous variables equal to zero, and simulating our estimated system with the temporary components alone. To obtain the permanent repercussions, we set the temporary components of the exogenous variables equal to zero, the pre-sample values of the endogenous variables equal to their actual values, and simulate the system with the permanent components alone.

Figure 8 describes the temporary repercussions and then adds them to the permanent repercussions. Observe that the sum of the temporary and permanent repercussions $\left(\mathcal{T}_{t}+\mathcal{P}_{t}\right)$ tracks the fitted unemployment rate reasonably closely. ${ }^{27}$

\footnotetext{
${ }^{27}$ As explained in Section 2.1., the temporary and permanent repercussions should add up to the dynamic fitted values of unemployment. This is indeed the case for each of the individual countries in our panel. However, for our panel as a whole this decomposition is not feasible due
} 
Observe that the permanent repercussions play the dominant role in explaining the steep upward climb of EU unemployment in the 1970s and early 1980s, whereas the temporary repercussions are dominant in the 1990s.

Figure 8: Temporary and permanent repercussions.

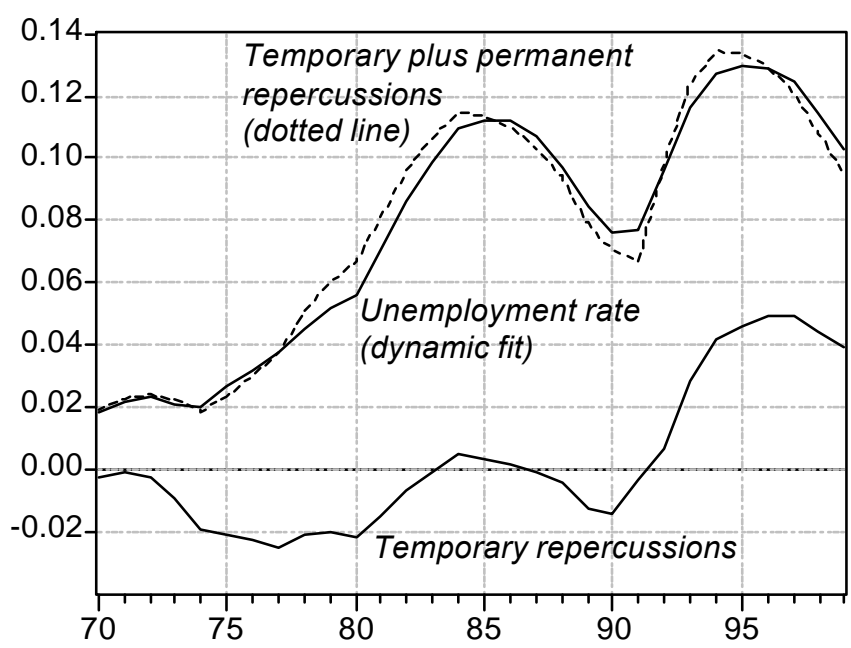

It can be shown that the temporary repercussions account for 32 percent of the variations in the actual unemployment rate, whereas the permanent repercussions account for 50 percent. To obtain these statistics, we regress the temporary repercussions on the permanent ones and save the residuals. We then regress the unemployment rate on this residual series. This gives $R^{2}=0.32$. Similarly, when we regress the unemployment rate on the residuals of a regression of the permanent repercussions on the temporary ones, we obtain $R^{2}=0.50$. In short, $32 \%$ is the portion of the unemployment variation explained by that part of the temporary repercussions which is uncorrelated with the permanent repercussions. Similarly, $50 \%$ of total unemployment variation can be attributed to this part of permanent repercussions which is uncorrelated with the temporary repercussions.

Whereas the sum of the individual contributions of the temporary and permanent repercussions to explaining unemployment variation is $82 \%$, the temporary

to the inherent nonlinearity in the definition of the unemployment rate: The EU unemployment rate is computed as the difference between the log of the EU labor force and the $\log$ of the EU employment level; this is not the same as the sum of the logs of the EU countries' labor forces minus the sum of the logs of the EU countries' employment. This accounts for the the discrepancy between the dynamic fitted values and the sum of temporary plus permanent components in Figure 8. 
and permanent repercussions can jointly explain $96 \%$ of the unemployment variation (this is the $R^{2}$ obtained by regressing the unemployment rate on both series). ${ }^{28}$

\subsection{Long-run Unemployment Effects and Lagged Adjustments}

We now decompose the temporary and permanent repercussions into long-run unemployment effects and the associated lagged adjustments.

We derive the long-run unemployment effects of the temporary components, $u_{t}^{L R}(T C)$, by setting permanent components equal to zero, setting the lag operators associated with all endogenous variables in our estimated system equal to unity, simulating the system, and deriving the associated unemployment time series. These $u_{t}^{L R}(T C)$ effects are shown in Figure 9. Observe that they are much more volatile than the temporary repercussions $\left(\mathcal{T}_{t}\right)$, with the cyclical swings corresponding to the major upturns and downturns in EU labor markets over the sample period: the recession of the mid-1970s following the first oil-price shock, the rise in unemployment around 1978 due to reduced capital accumulation (which was, in turn, a lagged response to the previous recession), the recession of the early 1980s following the second oil-price shock, the boom of the late 1980s, the recession of the early 1990s, and the boom of the late 1990s.

Figure 9: Unemployment variations from temporary shocks.

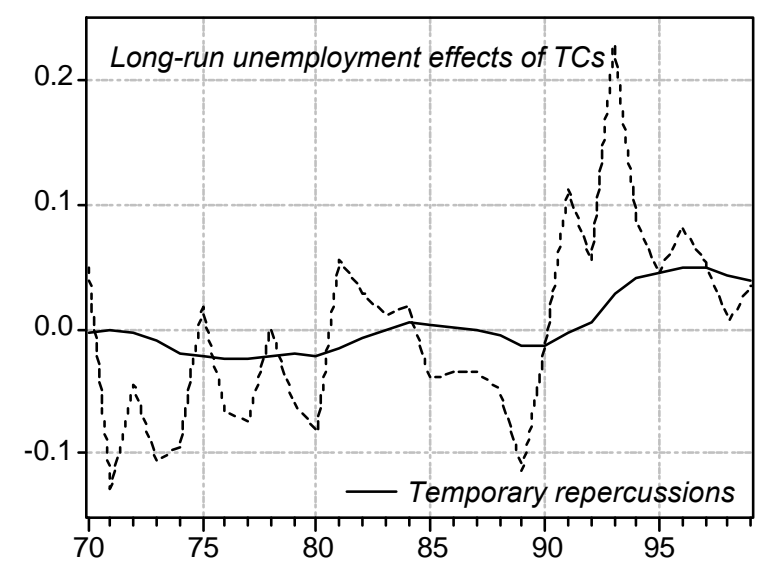

The difference between the two series, $\mathcal{T}_{t}-u_{t}^{L R}(T C)$, are accounted for by the lagged adjustments to the temporary shocks. Clearly the lagged adjustment processes have played two important roles in modifying the unemployment influence

\footnotetext{
${ }^{28}$ Due to the correlation between the temporary and permanent repercussions, there is a part in the explained variation of unemployment which cannot be attributed to either of the two series because there is no obvious way to divide it between them.
} 
of temporary shocks: (i) they are smoothed intertemporally and (ii) they are given persistent after-effects. For example, the large positive spikes in the $u_{t}^{L R}(T C)$ in the early 1980s and early 1990s is smoothed out, and the $u_{t}^{L R}(T C)$ remains high for about half a decade thereafter.

Along the same lines, long-run unemployment effects of the permanent components, $u_{t}^{L R}(P C)$, are obtained by setting temporary components equal to zero, setting the lag operators associated with all endogenous variables in our estimated system equal to unity, simulating the system, and deriving the associated unemployment time series. These effects are given in Figure 10. We identify the dynamic adjustments to the $P C s$ as the difference between the permanent repercussions and the long-run unemployment effects of the permanent components.

Observe that $u_{t}^{L R}(P C)$ lies well above the permanent repercussions in the first part of the sample period, and this helps explain the steep rise of European unemployment in the 1970s and first part of the 1980s. Here the lagged adjustment processes have played a major role in preventing the full effects of the permanent components from manifesting themselves. Thus the high long-run unemployment effects in the 1970s and early 1980s leads only to a slow and steady rise of the permanent repercussions.

Observe, furthermore that, from the mid-1980s onwards, $u_{t}^{L R}(P C)$ was slightly below the permanent repercussions, leading to a gradual fall in the permanent repercussions. On its own, this configuration would have led to a slow decline of the unemployment rate; but as it turned out, the bulge of temporary shocks in the early 1990s sent EU unemployment upwards again.

Why were the long-run unemployment effects of the permanent components so high in the 1970s and early 1980s? The underlying data show that $u_{t}^{L R}(P C)$ was so high in the first part of the 1970s because the labor supply increased markedly in the late 1960s and early 1970s, as the postwar baby-boom generation entered the labor force. A major reason why $u_{t}^{L R}(P C)$ remained so high throughout the 1970s was the productivity slow-down after the first oil-price shock and the accompanying drop in capital formation. In the late 1980s and 1990s, however, the working-age population grew less rapidly relative to the growth of the capital stock, and thus $u_{t}^{L R}(P C)$ fell gradually. 
Figure 10: Unemployment variations from permanent shocks.

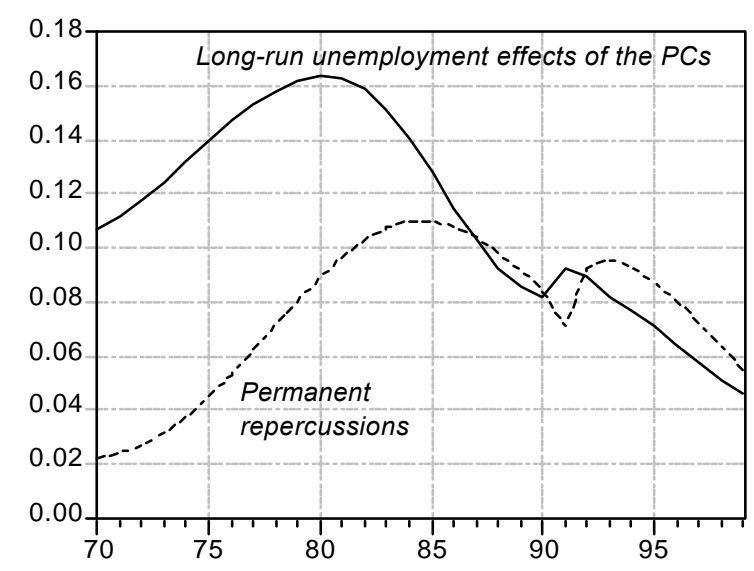

Figures 9 and 10 illustrate how dramatically the adjustment processes to temporary shocks differ from those to permanent shocks. This difference - temporary shocks are smoothed and have persistent after-effects, whereas permanent shocks are kept from manifesting themselves fully - provides an empirical justification for distinguishing between the temporary and permanent components. The figures also show that both the temporary and permanent repercussions had important roles to play in accounting for the movements in EU unemployment. The rise in EU unemployment over much of the 1970s and first half of the 1980s largely follows the permanent repercussions - particularly those associated with the movements in the capital stock and working-age population. However, the rise in EU unemployment in the first part of the 1990s is tracked by the temporary repercussions - particularly those associated with the movements in the interest rate and social security benefits.

\subsection{The Frictionless Equilibrium Unemployment Rate}

As noted, the FEU, or long-run unemployment rate $u_{t}^{L R}$, can be derived as the sum of the long-run unemployment effects of the temporary and permanent components. These are presented in Figure 11. The cyclical swings of the long-run unemployment rate of course follow the ups and down of the long-run unemployment effects of the temporary components. Over the longer run, observe that there are two large bulges of the long-run unemployment rate. The first - extending from the mid-1970s to the mid-1980s - is due primarily to $u_{t}^{L R}(P C)$, whereas the second - covering the first part of the 1990s - comes primarily from $u_{t}^{L R}(T C)$. 
Figure 11: Actual and long-run equilibrium rate of unemployment.

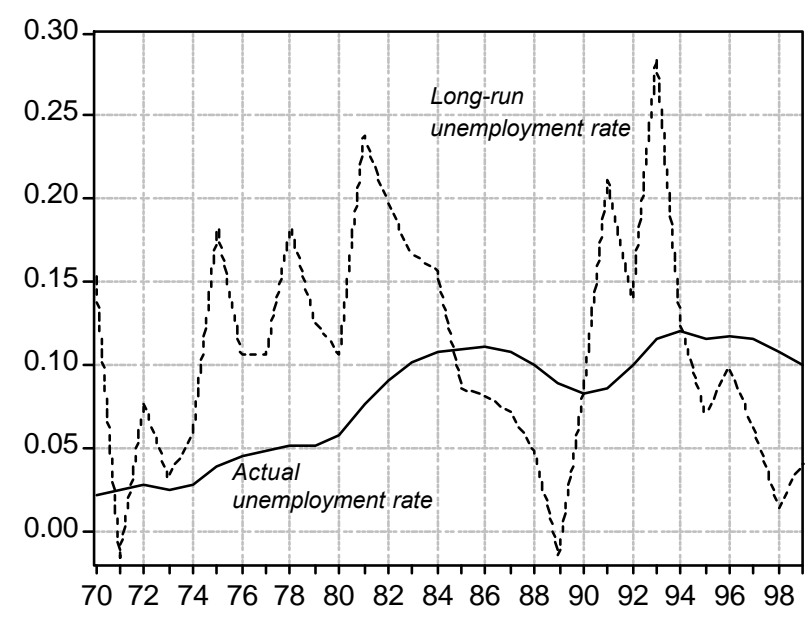

The long-run unemployment rate does not track the actual unemployment closely at all. Little of the variation in actual unemployment is accounted for by variations in the long-run unemployment rate: regressing the actual on the long-run unemployment rate yields an $R^{2}=0.007$. Like the $u_{t}^{L R}(T C)$ series, the long-run unemployment rate is far more volatile than the actual unemployment rate. Our empirical model suggests that, in the absence of the lagged labor market adjustment processes, EU unemployment would have been far higher than it actually was in the recession periods and far lower than it was in the boom times.

Note that the long-run unemployment rate provides some indication of the direction in which EU unemployment is moving. For instance, when the long-run rate was above the actual rate in the second half of the 1970s and first half of the 1980s, EU unemployment tended upwards; and when the long-run rate was below the actual rate in the second half of the 1980s and the second half of the 1990s, EU unemployment tended downwards. Nevertheless, the lagged adjustments to these long-run movements appear to have been very prolonged - so prolonged that the correlation of the actual and long-run unemployment rates is very small indeed.

On all these accounts, our analysis suggests strongly that the lagged adjustment processes have played an important role in determining the movements of EU unemployment.

\section{Single-Equation versus Multi-Equation Analysis}

The above analysis of unemployment stands in stark contrast to the many conventional empirical analyses that are based on single-equation models of unem- 
ployment. These models - whose structure may be summarized by equation (2.3), $u_{t}=\sum_{j=1}^{I} \phi_{j} u_{t-j}+\sum_{j=0}^{J} \boldsymbol{\theta}_{j}^{\prime} \mathbf{x}_{t-j}$ - may be understood as the reduced form of an equation system such as the one above. In this context, a particularly common way of deriving the FEU or NRU is to set the lag operators in this equation equal to unity, and obtaining the resulting unemployment rate, which is thus equivalent to the long-run unemployment rate of equation (2.7): $F E U_{t}=\left(1-\sum_{j=1}^{I} \phi_{j}\right)^{-1}\left(\sum_{j=0}^{J} \boldsymbol{\theta}_{j}^{\prime} \mathbf{x}_{t-j}\right)$. In this context, as noted, the FEU is the equilibrium unemployment rate at which there is no tendency for the unemployment rate to change, given the values of the exogenous variables. In this section, we explore the relation between our analysis and this conventional singleequation approach.

\subsection{The Single-Equation Approach}

To compare the two approaches, we find the FEU by estimating a single unemployment equation of the above type, choosing the same set of exogenous variables as those in our estimated system.

\section{Insert Table 8}

Figure 12: FEU, actual and fitted unemployment rates: Single-equation model

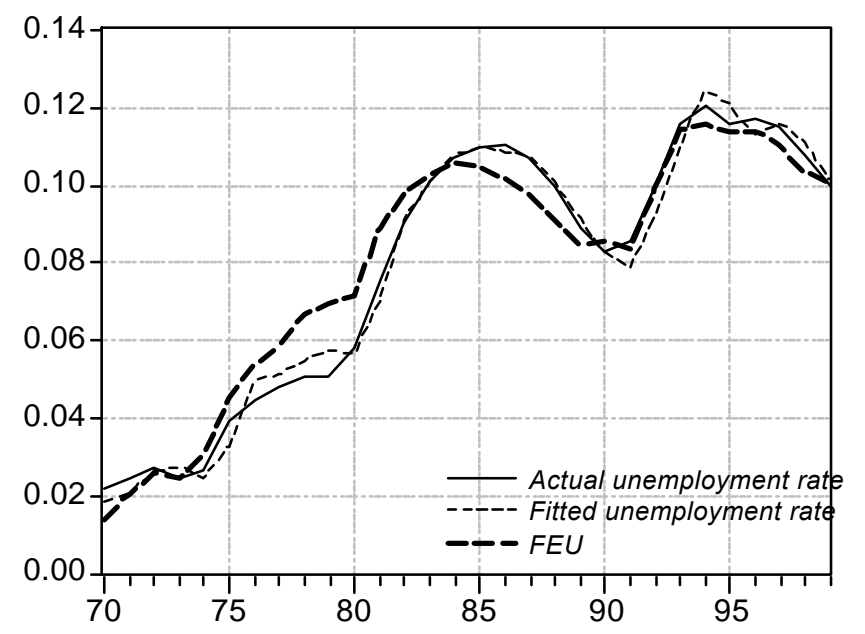

Table 8 presents two versions of the single-equation model, one using all the exogenous variables of our estimated system ${ }^{29}$ (Version 2 ) and the other - our preferred one - using only those exogenous variables that are statistically significant

\footnotetext{
${ }^{29}$ Note that in Version 2 all the exogenous variables are included and they are specified in the same way as in the estimated multi-equation system (e.g. the capital stock enters both through
} 
(Version 1). ${ }^{30}$ In the mainstream literature, a variety of other exogenous variables have of course also been used to explain unemployment. ${ }^{31}$ For our purposes, however, it suffices to focus on the exogenous variables used in our estimated equation system, since the underlying difference between our approach and the standard single-equation approach can be identified quite simply in this context. (It is also worth noting that most of the mainstream contributions tend to ignore or minimize the role of unemployment dynamics - through such means as Blanchard-Wolfer's method of taking 5-year averages of institutional variables and thus it is not surprising that they find that the NRU plays a major role whereas the dynamic unemployment adjustments play a minor one in accounting for unemployment movements.)

Figure 12 presents the resulting FEU, alongside the fitted and actual unemployment rates. Observe that this FEU - in marked contrast to the FEU associated with our estimated equation system above - closely follows the actual unemployment rate. How is this discrepancy between the standard single-equation FEU and our multi-equation FEU to be rationalized?

\subsection{Comparing the Two Approaches}

For expositional simplicity, consider the following two alternative models for estimating unemployment:

- a single-equation model (S-E) that involves the direct estimation of a single unemployment rate $(u)$ equation, and

- a multi-equation model (M-E) that estimates labor force $(l)$ and employment $(n)$ equations and then subtracts employment from the labor force ${ }^{32}$ to derive the unemployment rate equation, which we will call the reduced form unemployment equation.

To begin with, suppose that the regressors used in S-E are identical to those used in each of the equations in M-E. Then the two models may be expressed as

\footnotetext{
its level and its lagged difference).

${ }^{30}$ Although the interest rate is marginally significant, it is retained in Version 1 since it permits a better specification of the model.

${ }^{31}$ For example, Blanchard et al. (1991), Blanchard and Wolfers (2000), Phelps (1994), and Phelps and Zoega (2001) use wage-pressure variables such as union power, interest rates, asset prices, and institutional variables such as job security and the magnitude and duration of unemployment benefits.

${ }^{32}$ Recall that since the variables are in logs, we can approximate the unemployment rate as $u=l-n$.
} 
follows, with the S-E model as

$$
u=X_{1} \delta_{1}+X_{2} \delta_{2}+\varepsilon^{u}
$$

and the M-E model as

$$
\begin{gathered}
l=X_{1} \gamma_{1}+X_{2} \gamma_{2}+\varepsilon^{l}, \\
n=X_{1} \beta_{1}+X_{2} \beta_{2}+\varepsilon^{n},
\end{gathered}
$$

where $u, l$, and $n$ are vectors, the $X$ 's are matrices of explanatory variables (which can also include lagged dependent variables), the $\delta$ 's are coefficient vectors, and the $\varepsilon$ 's are white noise error terms. The reduced form unemployment equation is thus given by

$$
u=X_{1}\left(\gamma_{1}-\beta_{1}\right)+X_{2}\left(\gamma_{2}-\beta_{2}\right)+\left(\varepsilon^{l}-\varepsilon^{n}\right) .
$$

Least-squares estimation of the single equation model (5.1) gives

$$
\widehat{\delta}_{1}=\left(X_{1}^{\prime} M_{2} X_{1}\right)^{-1} X_{1}^{\prime} M_{2} u
$$

or

$$
\widehat{\delta}_{1}=\left(X_{1}^{\prime} M_{2} X_{1}\right)^{-1} X_{1}^{\prime} M_{2} l-\left(X_{1}^{\prime} M_{2} X_{1}\right)^{-1} X_{1}^{\prime} M_{2} n,
$$

where $M_{2}=I-X_{2}\left(X_{2}^{\prime} X_{2}\right)^{-1} X_{2}^{\prime}{ }^{33}$ (The expression for $\widehat{\delta}_{2}$ is symmetric with respect to the subscripts of the variables, and thus may be omitted for brevity.)

Estimation of the multi-equation model gives

$$
\widehat{\gamma}_{1}=\left(X_{1}^{\prime} M_{2} X_{1}\right)^{-1} X_{1}^{\prime} M_{2} l,
$$

and

$$
\widehat{\beta}_{1}=\left(X_{1}^{\prime} M_{2} X_{1}\right)^{-1} X_{1}^{\prime} M_{2} n
$$

Observe that

$$
\widehat{\delta}_{1}=\widehat{\gamma}_{1}-\widehat{\beta}_{1}
$$

(Symmetric results hold for $\delta_{2}, \gamma_{2}$, and $\beta_{2}$.) Consequently, we conclude that if the single-equation model (5.1) and each equation of the multi-equations model (5.2)-(5.3) have all identical regressors, then the two estimation procedures will

\footnotetext{
${ }^{33}$ See Greene (2000) for results on partitioned matrices.
} 
yield identical results. In short, it then makes no difference whether we obtain our estimates directly from the single equation (5.1) or from the reduced form unemployment (5.4).

Now, by contrast, suppose that the regressors used in the single-equation model are not identical to the regressors used in each of the equations in the multiequation model. For example, suppose that labor force and employment are given by

$$
\begin{gathered}
l=X_{2} \gamma_{2}+\varepsilon^{l}, \\
n=X_{1} \beta_{1}+\varepsilon^{n},
\end{gathered}
$$

respectively. Then the reduced form unemployment equation is

$$
u=X_{2} \gamma_{2}-X_{1} \beta_{1}+\left(\varepsilon^{l}-\varepsilon^{n}\right) .
$$

In this case, clearly, the two estimated models produce quite different results. The fitted values obtained from the previous reduced form unemployment equation are

$$
\widehat{u}=\left(X_{2}^{\prime} X_{2}\right)^{-1} X_{2}^{\prime} l-\left(X_{1}^{\prime} X_{1}\right)^{-1} X_{1}^{\prime} n,
$$

whereas the fitted values of the single-equation model (5.1) are

$$
\widehat{u}=X_{1}\left(X_{1}^{\prime} M_{2} X_{1}\right)^{-1} X_{1}^{\prime} M_{2}(l-n)+X_{2}\left(X_{2}^{\prime} M_{1} X_{2}\right)^{-1} X_{2}^{\prime} M_{1}(l-n) .
$$

In this context, there is an important empirical remark to be made, which enters the discussion surrounding the results obtained from single- or multi-equation models.

Needless to say, when structural multi-equation systems are estimated, it is generally not the case that each constituent equation has the same regressors. Thus it becomes impossible for the regressors of the S-E model to be identical to each equation in the M-E model. Then the S-E model can no longer be viewed as an unbiased summary of the M-E model. Rather, the detailed economic interactions portrayed in the M-E model - including the dynamic interactions among the various lagged adjustment processes - can no longer be captured in the S-E model. In short, the single-equation model becomes misleading. ${ }^{34}$

\footnotetext{
${ }^{34}$ Of course, a similar aggregation problem arises when the M-E model above is compared with a more disaggregated M-E model. The problem is overcome once increasing disaggregation yields no further diversity of regressors in the component equations.
} 
Figure 13: Unemployment repercussions in S-E and M-E models.

a. Temporary repercussions

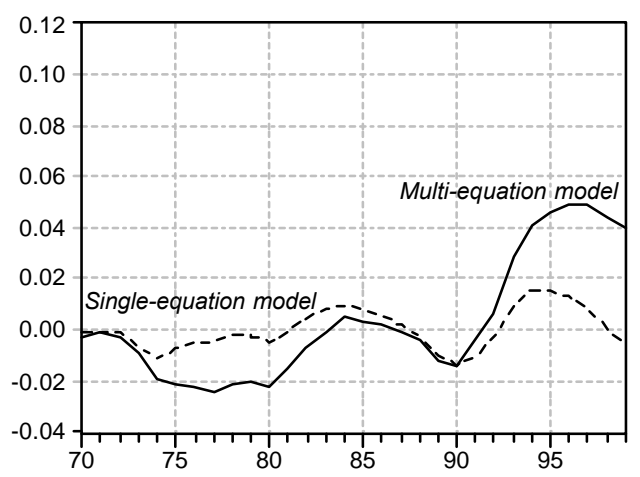

b. Permanent repercussions

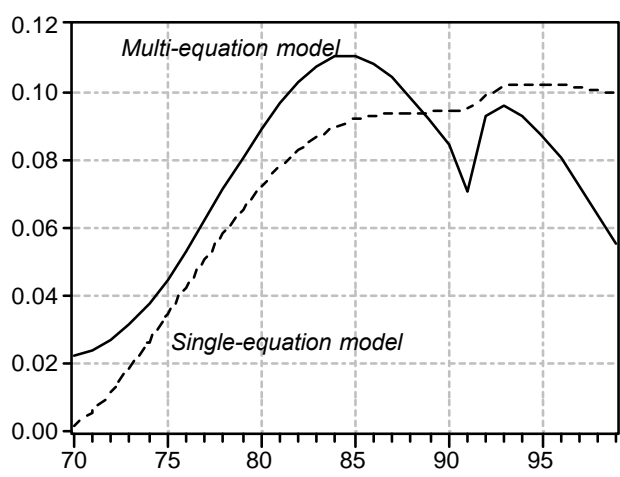

Consequently, it comes as no surprise that when the S-E model is used to derive the temporary and permanent repercussions, the results are quite different from those of the M-E model above, as shown in Figures 13a and 13b. Observe that the S-E model gives temporary repercussions a misleadingly small role in explaining the movements in EU unemployment: the temporary repercussions in the S-E model never account for as much as 2 percentage points of unemployment, and the S-E model misses the 1990s bulge in temporary repercussions that is identified by the M-E model. To compensate, the S-E model gives permanent repercussions a misleadingly large role the upward drift of EU unemployment over the sample period.

Overall, the high level of aggregation inherent in single-equation models introduces an interesting bias into the empirical analysis of unemployment movements: the role of the FEU (or NRU) is over-emphasized and, correspondingly, the role of lagged adjustments is under-emphasized. As a comparison of Figures 11 and 12 shows, the FEU tracks the actual unemployment rate closely in the S-E model (leaving little to be explained by dynamic adjustments) but not closely in the M-E model (leaving much more to be explained by dynamic adjustments). Thus, single-equation models are not a reliable way to evaluate the relative importance of long-run shifts versus lagged adjustments in explaining the evolution of EU unemployment.

\section{Conclusions}

This paper has examined some important questions for the analysis of EU unemployment: Have the long swings and upward drift of European unemployment over 
the past three decades been due primarily to changes in the underlying supplyand-demand relationships, causing shifts in the long-run equilibrium unemployment rates? Or have lagged adjustments to these shifts played an even more important role?

In examining lagged adjustment dynamics, we have seen that there are striking differences between the unemployment movements following temporary shocks and those following permanent shocks. Temporary shocks - such as changes in real interest rates, competitiveness, oil prices, and taxes - may have persistent after-effects on unemployment, whereas the long-run effects of permanent shocks - such as changes in the capital stock or working-age population - may take a long time to manifest themselves (inertia) or there may be over-shooting. On this account, it is important to distinguish between temporary and permanent shocks in the analysis of unemployment dynamics. What has been the relative importance of temporary and permanent shocks in accounting for the movements in EU unemployment?

To address these questions, we have estimated a dynamic panel data model for the EU countries over the last three decades. The model is an equation system comprising employment, wage, labor force and production equations, as well as a definition of the unemployment rate. In this context, we derived the unemployment repercussions of the temporary and permanent components of the exogenous variables, and we decomposed these repercussions into long-run unemployment effects and dynamic adjustments. We found that the dynamic adjustments in response to the permanent shocks played a large role in accounting for rise of EU unemployment in the 1970s and first half of the 1980s, whereas the dynamic adjustments in response to the temporary shocks played a large role in explaining the rise of EU unemployment in the early 1990s.

In broad outline, this methodology suggests the following explanation of European unemployment movements. In the late 1960s and early 1970s, the European labor force increased rapidly as the postwar baby-boom generation became adults and began looking for jobs. This large permanent shock took a long time to feed through European labor markets, leading to a steady rise in unemployment in the 1970s. This influence was augmented by the productivity slow-down of the mid-1970s that was accompanied by a downward shift in capital formation. The after-effects of these permanent changes, along with some temporary shocks - a rise in interest rates and a fall in competitiveness - kept European unemployment rising through the mid-1980s.

The labor force shock reversed itself in 1980s and 1990s, as the labor supply slowed down relative to the growth of the capital stock. This permanent shock also took a long time to manifest itself, contributing to the fall in European unemployment during the second half of the 1980s and the second half of the 1990s. 
Meanwhile, in the early 1990s, high real interest rates and low competitiveness (i.e. a low ratio of import prices to GDP deflators, due in part to the surging US productivity performance and other structural factors), were the temporary shocks that sent European unemployment upwards during the first part of the 1990s and it took some time before the unemployment rate came down significantly.

This account of the European unemployment problem - in which lagged adjustment processes play a central role in describing unemployment movements - is however at odds with the story suggested by the standard single-equation models, which attribute much of the medium- and longer-run unemployment movements to changes in the long-run unemployment equilibrium. We rationalize the discrepancy this approach and ours by showing that, on account of a dynamic aggregation problem, single-equation unemployment models give a biased analysis of unemployment, over-emphasizing the role of long-run shifts and under-emphasizing the role of dynamic adjustments. We conclude that whereas there were substantial shifts in the long-run EU unemployment rate over the sample period, the prolonged dynamic adjustments are indispensable in providing a balanced analysis of European unemployment. 


\section{References}

[1] Baltagi, B. H. (1995): Econometric Analysis of Panel Data, New York: Wiley.

[2] Baltagi, B. H. and J. M. Griffin (1997): "Pooled estimators vs. their heterogeneous counterparts in the context of dynamic demand for gasoline", Journal of Econometrics, No. 77, 303-327.

[3] Baltagi, B. H. and Kao (2000): "Nonstationary Panels, Cointegration in Panels and Dynamic Panels: A Survey", mimeo.

[4] Banerjee A. (1999): "Panel Data Unit Roots and Cointegration: An Overview", Oxford Bulletin of Economics and Statistics, special issue, 607629.

[5] Bertola, G. (1990), "Job Security, Employment and Wages," European Economic Review, 34, 851-86.

[6] Bertola, G., Boeri, T. and Nicoletti, G. (2001): "Welfare and Employment in a United Europe", MIT Press.

[7] Bertola, G., and G. Saint-Paul, (1994), "A Model of labor Demand with Linear Adjustment Costs," Labour Economics, 1, 303-326.

[8] Blanchard, O.J. and L. Summers (1986), "Hysteresis and the European Unemployment Problem," NBER Macroeconomics Annual, vol. 1, Cambridge, Mass: MIT Press, 15-71.

[9] Blanchard, O.J. and J. Wolfers (2000): "The Role of Shocks and Institutions in the Rise of European Unemployment: The Aggregate Evidence", Economic Journal, 110, March.

[10] Daveri, F. and G. Tabellini (2000): Unemployment, Growth and Taxation in Industrial Countries", Economic Policy, 0 (30), 47-88.

[11] Díaz, P., and D.J. Snower (1996), "Employment, Macroeconomic Fluctuations and Job Security," CEPR Discussion Paper No. 1430.

[12] Fisher, R. A. (1932): Statistical Methods for Research Workers, Edinbutgh: Oliver \& Boyd.

[13] Greene, W. (2000): Econometric Analysis, 4th Edition, New York: Prentice Hall. 
[14] Harris, R. D. F. and E. Tzavalis (1999):"Inference for Unit Roots in Dynamic Panels where the Time Dimension is Fixed", Journal of Econometrics, 91, 201-226.

[15] Henry, S.G.B., M. Karanassou, and D.J. Snower (2000), "Adjustment Dynamics and the Natural Rate", Oxford Economic Papers, 52, 178-203.

[16] Hsiao, C. (1986): Analysis of Panel Data, Cambridge: Cambridge University Press.

[17] Im, K. S., Pesaran, M. H., and Y. Shin (1997): "Testing for Unit Roots in Heterogeneous Panels", mimeo, Department of Applied Economics, University of Cambridge.

[18] Im, K. S., Pesaran, M. H., and R. Smith (1996): Dynamic Linear Models for Heterogeneous Panels, p. 145-195 of Matyas and Sevestre.

[19] Karanassou, M., and D.J. Snower (1997), "Is the Natural Rate a Reference Point?", 1997, European Economic Review, 41, 559-569.

[20] Karanassou, M., and D.J. Snower (1998), "How Labor Market Flexibility Affects Unemployment: Long-Term Implications of the Chain Reaction Theory", 1998, Economic Journal, 108, May, 832-849.

[21] Karanassou, M., and D.J. Snower (2002), "Unemployment Invariance," mimeo.

[22] Kiviet, J. F. (1995): "On bias, inconsistency, and efficiency of various estimators in dynamic panel data models", Journal of Econometrics, 68, 53-78.

[23] Layard, P.R.J., Nickell, S.J. and R. Jackman (1991): Unemployment: Macroeconomic Performance and the Labor Market, Oxford: Oxford University Press.

[24] Levin, A. and C. F. Lin (1993): "Unit Root Tests in Panel Data: New Results", Department of Economics, University of California at San Diego, Discussion Paper No. 93-56.

[25] Lindbeck, A., and D.J. Snower (1987), "Union Activity, Unemployment Persistence, and Wage-Employment Ratchets," European Economic Review, 31, Feb., 157-167.

[26] Maddala, G. S. and S. Wu (1999): “A comparative Study of Unit Root Tests with Panel Data and a New Simple Test", Oxford Bulletin of Economics and Statistics, special issue, 631-652. 
[27] Pesaran, M.H. and R. Smith (1995): "Estimating long-run relationships from dynamic heterogeneous panels", Journal of Econometrics, 68, 79-113.

[28] Phelps, E. S. (1994): Structural Booms: The Modern Equilibrium Theory of Unemployment, Interest and Assets, Harvard University Press, Cambridge (MA).

[29] Phelps, E. and G. Zoega (2001): "Structural booms: productivity expectations and asset valuations," Economic Policy, 32, April, 85-126.

[30] Phillips, P. C. B. and H. R. Moon (1999): "Linear Regression Limit Theory for Nonstationary Panel Data", Econometrica, Vol. 67, No. 5, 1057-1111.

[31] Robertson, D. and J. Symons (1992): "Some Strange Properties of Panel Data Estimators," Journal of Applied Econometrics, 7, 175-189.

[32] Smith, R. P. (2000): "Estimation and inference with non-stationary panel time-series data", mimeo. 


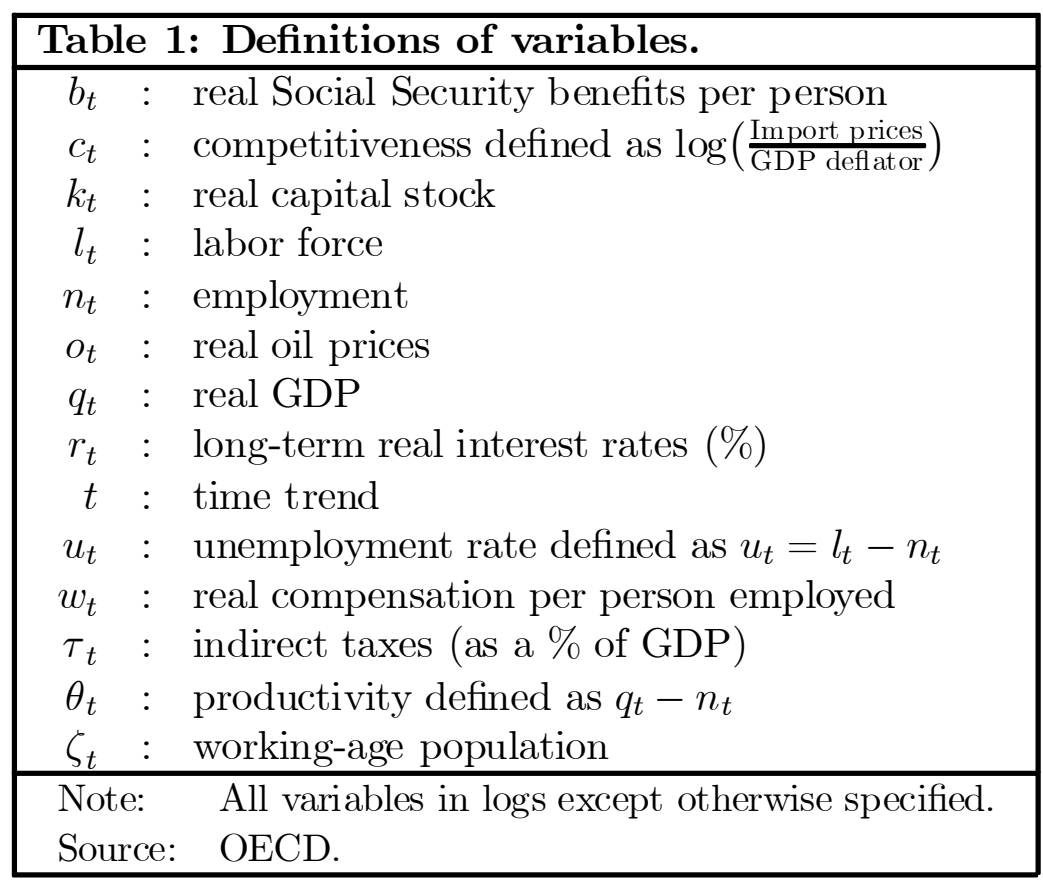

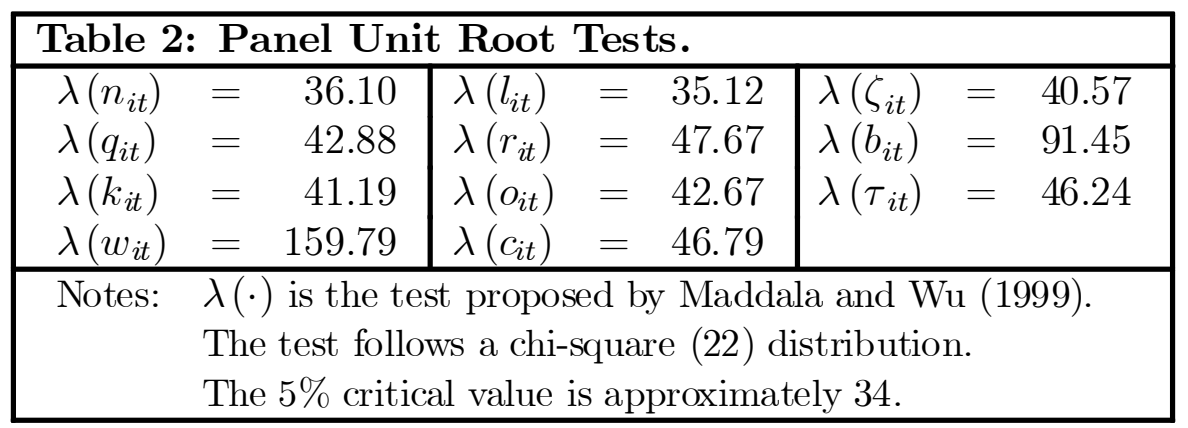




\begin{tabular}{|lrll|}
\hline \multicolumn{4}{|c|}{ Table 3: Labor demand equation. } \\
\hline \multicolumn{5}{|c}{ Dependent variable: } & $n_{t}$ \\
& Coefficient & St. e. & Prob. \\
$n_{t-1}$ & 1.42 & 0.039 & 0.000 \\
$n_{t-2}$ & -0.48 & 0.035 & 0.000 \\
$w_{t}$ & -0.03 & 0.012 & 0.011 \\
$k_{t}$ & 0.02 & 0.009 & 0.035 \\
$\Delta k_{t}$ & 1.99 & 0.070 & 0.000 \\
$\Delta k_{t-1}$ & -1.65 & 0.093 & 0.000 \\
$c_{t}$ & 0.02 & 0.006 & 0.003 \\
$r_{t}$ & -0.001 & 0.000 & 0.019 \\
$t$ & 0.001 & 0.000 & 0.044 \\
\multicolumn{4}{r}{} \\
\hline$R^{2}$ & 0.999 & \\
$M L L$ & 1108.9 & \\
\hline
\end{tabular}

\begin{tabular}{|lrrr|}
\hline Table 4: Wage equation. \\
\hline \multicolumn{4}{|c|}{ Dependent variable: $w_{t}$} \\
& Coefficient & St. e. & Prob. \\
$w_{t-1}$ & 0.97 & 0.051 & 0.000 \\
$w_{t-2}$ & -0.14 & 0.045 & 0.002 \\
$u_{t}$ & -0.29 & 0.045 & 0.000 \\
$\theta_{t}$ & 0.50 & 0.056 & 0.000 \\
$\theta_{t-1}$ & -0.36 & 0.052 & 0.000 \\
$b_{t}$ & 0.14 & 0.020 & 0.000 \\
$b_{t-1}$ & -0.12 & 0.022 & 0.000 \\
$o_{t}$ & 0.005 & 0.002 & 0.020 \\
$\tau_{t}$ & -0.59 & 0.180 & 0.001 \\
$\tau_{t-1}$ & 0.41 & 0.189 & 0.030 \\
\hline$R^{2}$ & & & \\
$M L L$ & 912.0 & & \\
\hline \multicolumn{4}{|c}{} \\
\hline
\end{tabular}




\begin{tabular}{|lrrr|}
\hline \multicolumn{4}{|c|}{ Table 5: Labor supply equation. } \\
\hline \multicolumn{4}{|c|}{ Dependent variable: $l_{t}$} \\
& Coefficient & St. e. & Prob. \\
$l_{t-1}$ & 1.00 & 0.031 & 0.000 \\
$l_{t-2}$ & -0.08 & 0.026 & 0.005 \\
$u_{t}$ & -0.04 & 0.019 & 0.060 \\
$\Delta u_{t}$ & -0.21 & 0.037 & 0.000 \\
$w_{t}$ & -0.06 & 0.025 & 0.019 \\
$w_{t-1}$ & 0.05 & 0.025 & 0.039 \\
$\zeta_{t}$ & 1.11 & 0.037 & 0.000 \\
$\zeta_{t-1}$ & -1.00 & 0.043 & 0.000 \\
& & & \\
\hline$R^{2}$ & 0.999 & & \\
$M L L$ & 1151.4 & \\
\hline \multicolumn{4}{|c}{} \\
\hline
\end{tabular}

\begin{tabular}{|c|c|c|c|}
\hline \multicolumn{4}{|c|}{ Table 6: Production fu } \\
\hline & Coefficient & St. e. & Prob. \\
\hline$q_{t-2}$ & -0.25 & 0.025 & 0.000 \\
\hline$k_{t}$ & 0.02 & 0.013 & 0.095 \\
\hline$n_{t}$ & 0.09 & 0.019 & 0.000 \\
\hline$o_{t}$ & -0.004 & 0.002 & 0.047 \\
\hline$t$ & 0.004 & 0.001 & 0.000 \\
\hline$\overline{R^{2}}$ & 0.999 & & \\
\hline$M L L$ & 1019.1 & & \\
\hline
\end{tabular}




\begin{tabular}{|c|c|c|c|}
\hline \multicolumn{4}{|c|}{ Table 7: Homogenous vs. Heterogenous Panels. } \\
\hline & $S I C_{\text {pooled }}$ & & $\overline{S I C_{\text {individual }}}$ \\
\hline Labor Demand: & 1051.25 & $>$ & 1032.12 \\
\hline Wage Setting: & 851.83 & $>$ & 810.05 \\
\hline Labor Force: & 1096.94 & $>$ & 1089.98 \\
\hline Production Function: & 972.48 & $>$ & 862.59 \\
\hline \multicolumn{4}{|c|}{$\begin{array}{ll}\text { Notes: } & \text { The statistics were computed using }(3.4) \text { and }(3.5) \text {. } \\
& \text { The model that maximizes the selection criterion is preferred. }\end{array}$} \\
\hline
\end{tabular}

\begin{tabular}{|c|c|c|c|c|c|c|}
\hline \multicolumn{7}{|c|}{ Dependent variable: $u_{t}$} \\
\hline & \multicolumn{3}{|c|}{ Version 1} & \multicolumn{3}{|c|}{ Version 2} \\
\hline & Coefficient & St. e. & Prob. & Coefficient & St. e. & Prob. \\
\hline$u_{t-1}$ & 1.23 & 0.05 & 0.00 & 1.26 & 0.05 & 0.00 \\
\hline$u_{t-2}$ & -0.51 & 0.04 & 0.00 & -0.43 & 0.04 & 0.00 \\
\hline$k_{t}$ & -0.014 & 0.01 & 0.02 & -0.008 & 0.01 & 0.14 \\
\hline$\Delta k_{t}$ & -0.37 & 0.06 & 0.00 & -0.57 & 0.08 & 0.00 \\
\hline$\Delta k_{t-1}$ & - & - & - & 0.27 & 0.06 & 0.00 \\
\hline$c_{t}$ & - & - & - & -0.001 & 0.01 & 0.92 \\
\hline$r_{t}$ & 0.024 & 0.019 & 0.21 & 0.016 & 0.018 & 0.38 \\
\hline$\tau_{t}$ & - & - & - & 0.07 & 0.08 & 0.36 \\
\hline$\tau_{t-1}$ & - & - & - & -0.05 & 0.08 & 0.51 \\
\hline$o_{t}$ & - & - & - & -0.001 & 0.00 & 0.74 \\
\hline$b_{t}$ & 0.02 & 0.01 & 0.00 & 0.08 & 0.01 & 0.00 \\
\hline$b_{t-1}$ & - & - & - & -0.07 & 0.01 & 0.00 \\
\hline$\zeta_{t}$ & 0.18 & 0.04 & 0.00 & 0.32 & 0.05 & 0.00 \\
\hline$\zeta_{t-1}$ & -0.13 & 0.04 & 0.00 & -0.29 & 0.05 & 0.00 \\
\hline$R^{2}$ & 0.979 & & & 0.984 & & \\
\hline$M L L$ & 1081.1 & & & 1124.0 & & \\
\hline
\end{tabular}




\section{IZA Discussion Papers}

\begin{tabular}{|c|c|c|c|c|}
\hline No. & Author(s) & Title & Area & Date \\
\hline 514 & F. Schneider & $\begin{array}{l}\text { The Size and Development of the Shadow } \\
\text { Economies of } 22 \text { Transition and } 21 \text { OECD } \\
\text { Countries }\end{array}$ & 4 & $06 / 02$ \\
\hline 515 & $\begin{array}{l}\text { J. Hurley } \\
\text { R. Vaithianathan } \\
\text { T. F. Crossley } \\
\text { D. Cobb-Clark }\end{array}$ & $\begin{array}{l}\text { Parallel Private Health Insurance in Australia: } \\
\text { A Cautionary Tale and Lessons for Canada }\end{array}$ & 3 & $06 / 02$ \\
\hline 516 & H. Bonin & $\begin{array}{l}\text { Eine fiskalische Gesamtbilanz der Zuwanderung } \\
\text { nach Deutschland }\end{array}$ & 7 & $06 / 02$ \\
\hline 517 & E. Tekin & $\begin{array}{l}\text { Child Care Subsidies, Wages, and Employment } \\
\text { of Single Mothers }\end{array}$ & 3 & $06 / 02$ \\
\hline 518 & $\begin{array}{l}\text { P. Carneiro } \\
\text { J. J. Heckman }\end{array}$ & $\begin{array}{l}\text { The Evidence on Credit Constraints in } \\
\text { Post-Secondary Schooling }\end{array}$ & 5 & $06 / 02$ \\
\hline 519 & $\begin{array}{l}\text { S. Cohen } \\
\text { Z. Eckstein }\end{array}$ & $\begin{array}{l}\text { Labor Mobility of Immigrants: Training, } \\
\text { Experience, Language and Opportunities }\end{array}$ & 1 & $06 / 02$ \\
\hline 520 & U. Sunde & $\begin{array}{l}\text { Unobserved Bilateral Search on the Labor } \\
\text { Market: A Theory-Based Correction for a } \\
\text { Common Flaw in Empirical Matching Studies }\end{array}$ & 1 & 06/02 \\
\hline 521 & $\begin{array}{l}\text { U. Sunde } \\
\text { R. Fahr }\end{array}$ & $\begin{array}{l}\text { Employment Status, Endogenous Regional } \\
\text { Mobility, and Spatial Dependencies in Labor } \\
\text { Markets }\end{array}$ & 1 & $06 / 02$ \\
\hline 522 & $\begin{array}{l}\text { S.-Å. Dahl } \\
\varnothing . \text { A. Nilsen } \\
\text { K. Vaage }\end{array}$ & $\begin{array}{l}\text { Gender Differences in Early Retirement } \\
\text { Behaviour }\end{array}$ & 3 & $06 / 02$ \\
\hline 523 & $\begin{array}{l}\text { J. Falkinger } \\
\text { V. Grossmann }\end{array}$ & $\begin{array}{l}\text { Workplaces in the Primary Economy and Wage } \\
\text { Pressure in the Secondary Labor Market }\end{array}$ & 3 & $07 / 02$ \\
\hline 524 & $\begin{array}{l}\text { J. J. Dolado } \\
\text { F. Felgueroso } \\
\text { J. F. Jimeno }\end{array}$ & $\begin{array}{l}\text { Recent Trends in Occupational Segregation by } \\
\text { Gender: A Look Across the Atlantic }\end{array}$ & 2 & 07/02 \\
\hline 525 & $\begin{array}{l}\text { J. J. Heckman } \\
\text { C. Heinrich } \\
\text { J. Smith }\end{array}$ & The Performance of Performance Standards & 6 & 07/02 \\
\hline 526 & $\begin{array}{l}\text { E. Leuven } \\
\text { H. Oosterbeek }\end{array}$ & $\begin{array}{l}\text { A New Approach to Estimate the Wage Returns } \\
\text { to Work-Related Training }\end{array}$ & 6 & 07/02 \\
\hline 527 & J. C. van Ours & The Locking-in Effect of Subsidized Jobs & 4 & $07 / 02$ \\
\hline 528 & $\begin{array}{l}\text { P. Manzini } \\
\text { M. Mariotti }\end{array}$ & $\begin{array}{l}\text { Arbitration and Mediation: An Economic } \\
\text { Perspective }\end{array}$ & 3 & 07/02 \\
\hline 529 & $\begin{array}{l}\text { J. M. Orszag } \\
\text { D. Snower }\end{array}$ & Incapacity Benefits and Employment Policy & 3 & 07/02 \\
\hline 530 & $\begin{array}{l}\text { M. Karanassou } \\
\text { D. Snower }\end{array}$ & Unemployment Invariance & 3 & 07/02 \\
\hline 531 & $\begin{array}{l}\text { M. Karanassou } \\
\text { H. Sala } \\
\text { D. Snower }\end{array}$ & $\begin{array}{l}\text { Unemployment in the European Union: A } \\
\text { Dynamic Reappraisal }\end{array}$ & 3 & $07 / 02$ \\
\hline
\end{tabular}

